\title{
Research Paper \\ The Effects of Mental Self-care Training on Mental Health and Academic Achievement in Students
}

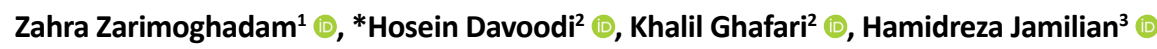

1. Department of Psychology, Faculty of Humanities, Khomein Branch, Islamic Azad University, Khomein, Iran.

2. Department of Educational Sciences, Faculty of Humanities, Garmsar Branch, Islamic Azad University, Garmsar, Iran.

3. Department of Psychiatry, School of Medical, Arak University of Medical Sciences, Arak, Iran.

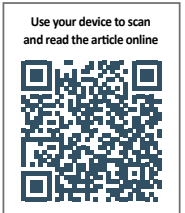

Citation: Zarimoghadam Z, Davoodi H, Ghafari Kh, Jamilian H. [The Effects of Mental Self-care Training on Mental Health and Academic Achievement in Students (Persian)]. Journal of Arak University of Medical Sciences (JAMS). 2021; 24(1):150167. https://doi.org/10.32598/JAMS.24.1.6155.1

doi) $h$ https://doi.org/10.32598/JAMS.24.1.6155.1

Keywords:

Mental self-care

Training, Academic

Achievement, Mental

health, Students

\section{A B S TRACT}

Background and Aim The development of any society depends on the educational system of that society. The educational system can be efficient and successful when considering the academic performance of learners in different courses. This study aimed to investigate the effects of mental self-care education on students' mental health and academic motivation.

Methods \& Materials This was a quasi-experimental study with unequal control and experimental groups. The statistical population of this study was students referring to school counseling centers; 40 of them ( $n=20 /$ group) were selected by random sampling method. The Depression, Anxiety, and Stress Scale - 21 Items (DASS21), and Academic Performance Rating Scale were used to collect the necessary data. Psychological self-care training was presented to the experimental group in ten 2-hour sessions. Then, a posttest was conducted on the study groups. Data analysis was performed using Multivariate Analysis of Covariance (MANCOVA).

Ethical Considerations This article was approved by the Ethics Committee of the Islamic Azad University, Khomeini Branch (Code: IR.IAU.ARAK.REC.1399.001).

Results The obtained findings indicated that mental self-care education was effective on students' mental health $(\mathrm{P}<0.05)$. Furthermore, psychological self-care education was ineffective on students' academic motivation.

Conclusion Mental self-care education was used to improve mental health; however, this training did not affect academic motivation in the examined subjects.

\section{Extended Abstract}

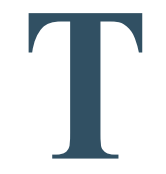

\section{Introduction}

he development of any society depends on the educational system of that society. The educational system can be efficient and successful when considering the academic performance of learners in different periods. School years are among the most basic years of children's lives. School experience significantly impacts academic success and mental health in adulthood. Neglecting mental health promotion in schools complicates any change, decision, or treatment plan. School is a unique opportunity and a key place to improve the lives and mental health of children and adolescents. Mental health is among the most important topics in psychology and psychiatry. Besides, mental health illnesses are on the rise.

* Corresponding Author:

Hosein Davoodi, PhD.

Address: Department of Educational Sciences, Faculty of Humanities, Garmsar Branch, Islamic Azad University, Garmsar, Iran.

Tel: +98 (918) 5284168

E-mail: davoudi_1351@yahoo.com 
Numerous studies suggested that organizing mental health services in schools is a fundamental strategy for promoting the health of students and ultimately society as a whole. This study aimed to investigate the effects of mental self-care education on students' mental health and academic motivation.

\section{Materials and Methods}

This was a quasi-experimental study with a pretest-posttest and a control group design. The statistical population of this study consisted of students referring to the school counseling center. First, 40 individuals were randomly selected by screening method; those who presented decreased mental health status and academic motivation were selected and randomly assigned to the experimental and control groups. Initially, those who were willing to participate in the present study were invited to the counseling center. In the briefing session, general explanations about the research process and educational sessions were provided to them. Then, a pretest was performed on them. Next, the training sessions began for the experimental group (Table 1); however, the controls received no training. At the end of the sessions, a posttest was conducted on the experimental and control groups. The collected data were analyzed using Multivariate Analysis of Covariance (MANCOVA) (Table 2).
The following tools were employed in this research:

A) Academic Performance Rating Scale: This 15-item questionnaire measures 3 subscales of behavioral, emotional, and cognitive motivation.

B) The Depression, Anxiety and Stress Scale-21 Items (DASS-21): This inventory is used to measure stress, anxiety, and depression. The DASS-21 has 21 questions. Besides, the final score of each item is obtained by the sum of the scores of the related questions.

\section{Results}

The present research results revealed a significant difference between the experimental and control groups in the dependent variables. Therefore, mental self-care training improved the combined dependent variables (mental health $\&$ academic motivation). Each variable was separately investigated and analyzed.

The collected results indicated that the components of mental health variables (depression, anxiety, stress) revealed a significant difference between the study groups at a $95 \%$ confidence interval $(\mathrm{P}>0.05)$. In other words, psychological self-care training improved the components of self-care. However, the MANCOVA results on the adjusted scores of the variable of academic motivation presented no significant difference between the research groups $(\mathrm{P}<0.05)$ (Table 2).

Table 1. The contents of the training sessions in the present study

\begin{tabular}{cc}
\hline Sessions & Contents \\
\hline One & Subject: Communication skills \\
\hline Two & Subject: Anger management \\
\hline Three & Subject: Stress management \\
\hline Four & Subject: Conflict resolution \\
\hline Five & Subject: Resilience \\
\hline Six & Subject: Self-care in depression \\
\hline Seven & Topic: Self-care in cyberspace \\
\hline Eghit & Topic: Self-care in domestic violence \\
\hline Nine & Topic: Self-care in sleep problems \\
\hline Ten & Subject: Self-care in addiction \\
\hline
\end{tabular}


Table 2. MANCOVA data concerning the research variables

\begin{tabular}{cccccccc}
\hline Source & Component & Total Squares & df & Means Squares & $\mathbf{F}$ & $\mathbf{P}$ & Effect Size \\
\hline \multirow{4}{*}{ Depression } & 25.77 & 1 & 25.77 & 29.23 & 0.00 & 0.46 \\
Error & 29.97 & 34 & 0.88 & & & \\
& Anxiety & 32.19 & 1 & 32.19 & 1992 & 0.00 & 0.36 \\
& Error & 54.92 & 34 & 1.61 & & 0.45 \\
& Stress & 31.94 & 1 & 31.94 & 28.79 & 0.00 & \\
& Error & 37.71 & 34 & 1.10 & & & 0.39 \\
\end{tabular}

The obtained findings indicated that mental self-care training was effective on students' mental health status. Mental health included 3 dimensions of depression, anxiety, and stress. Depression provided an effect size of 0.46 , self-care education has increased life enthusiasm and motivation for success and has reduced the symptoms of depression ( $\mathrm{P}>0.05$ ) (Table 2). Anxiety's effect size equaled 0.36; selfcare training has reduced anxiety among students $(\mathrm{P}>0.05)$ (Table 2). The effect size of stress was measured as 0.45 ; self-care training has reduced stress $(\mathrm{P}>0.05)$ (Table 2). The effect size of motivation equaled 0.02 ; self-care has not affected motivation in the study subject $(\mathrm{P}<0.05)$ (Table 2 ).

\section{Discussion and Conclusion}

This study examined the effects of mental self-care education on students' mental health and academic motivation. The relevant results indicated that mental self-care education improved mental health; however, it did not affect academic motivation and its level remained unchanged. Mental health addressed 3 dimensions of depression, anxiety, and stress.

According to cognitive theory, depression results from specific cognitive distortions in individuals. In psychological self-care, targeting distortions improves cognitive distortions in the depressed subject.

Depression is among the most common and debilitating problems in adolescents. School-Age individuals have certain characteristics that can cause depressive symptoms in them and prevent them from studying. Self-care education allows an individual to increase self-confidence, selfesteem, enthusiasm for life, and motivation for success; it can reduce the symptoms of depression in adolescents. To improve the condition of students, psychological self-care education can be used for them in all aspects of life, including education. Self-care education teaches the student the skills of using one's health resources; ultimately, it improves health, reduces anxiety, and increases the quality of life in adolescents. By learning mental self-care, individuals can cope with difficult situations and maintain a positive and constructive attitude towards life's problems. They can cope well with difficult situations and reduce their stress; accordingly, psychological self-care training was effective on students' stress.

This study indicated that psychological self-care education did not affect students' academic motivation. The purpose of psychological self-care education is to improve the student's psychological performance; it does not monitor the educational, learning, and educational aspects of academic life. Thus, psychological self-care has not been effective on students' academic motivation. Among the variables that may affect the result of the research, we can mention the synchronicity, internal validity, and the sample of the available research.

\section{Ethical Considerations}

\section{Compliance with ethical guidelines}

This article was approved by the Ethics Committee of the Islamic Azad University, Khomeini Shahr Branch (Code: IR.IAU.ARAK.REC.1399.001). 
Funding

The article was extracted from the $\mathrm{PhD}$. dissertation of the second author at the Department of Psychology and Counseling, Faculty of Humanities, Islamic Azad University, Khomeini Branch.

\section{Authors' contributions}

Conceptualization, research design: Zahra Zari Moghadam and Hossein Davoodi; Methodology, data analysis: Zahra Zari Moghadam and Hossein Davoodi; Data collection: All authors.

Conflicts of interest

The authors declared no conflicts of interest. 
This Page Intentionally Left Blank 


\title{
اثربخشى آموزش خودمراقبتى روانى بر سلامت روان و اشتياق تحصيلى دانشآموزان مقطع متوسطه دوم أموز
}

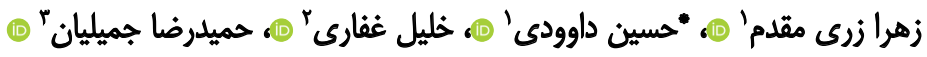 \\ I. كروه روانشناسى، دانشكده علوم انسانى، واحد خمينى شهر، دانشَّاه آزاد اسلامى، خمين، ايران.

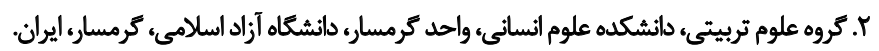

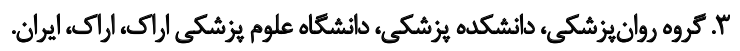

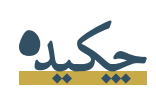

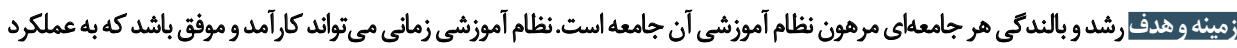

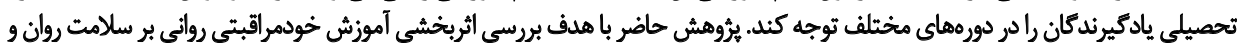

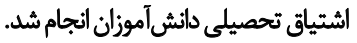

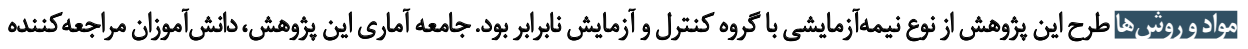

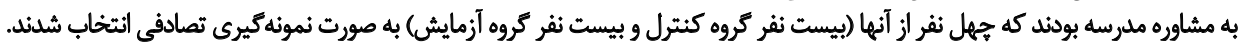

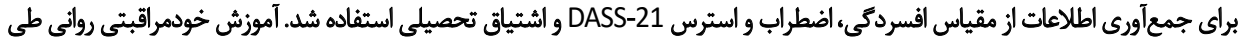

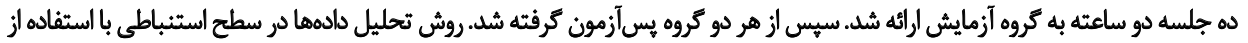

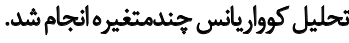

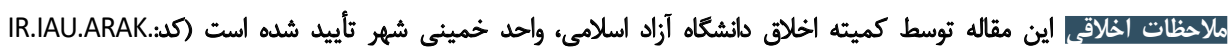
(REC.1399.001

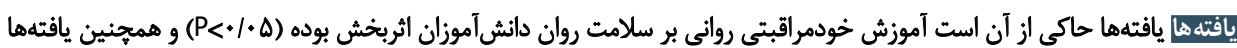

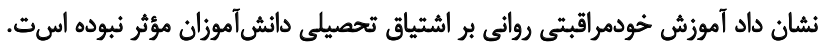

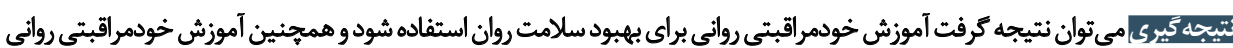
بر اشتياق تحصيلى اثرى نداشته است.

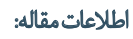

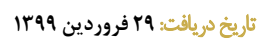

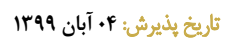

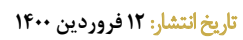

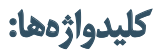

آموزش خودمراقبتئي رواني، اشتياق تحصيلي، سيلامث روانه دانش آموزان

در مباحث مربوط به تعليم و تربيت، داشتن اطلاعات و دانش

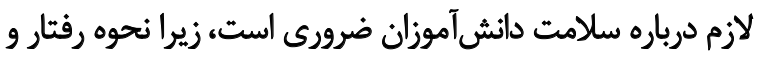

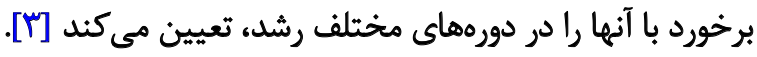

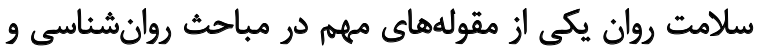

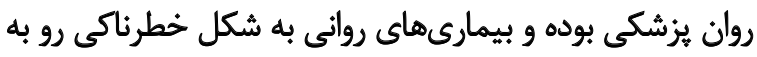

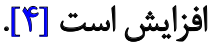
آمارهاى موجود شيوع بالاى مشكلات روانى، بهويرُه افسردكى

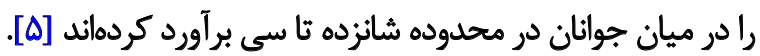

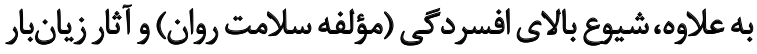

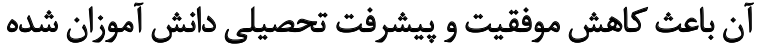

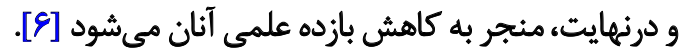

سالهاى مدرسه جزء اساسىترين سال هاى زندگى كودكان

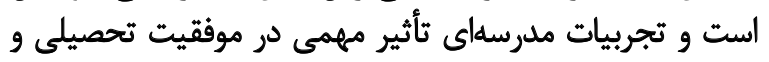

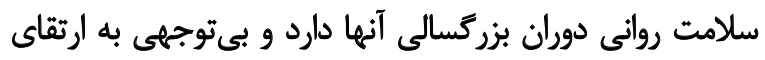

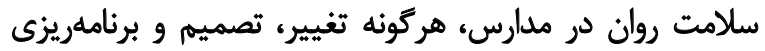

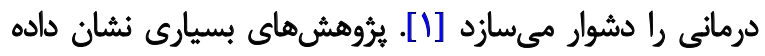

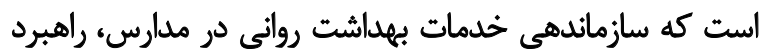

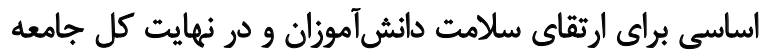

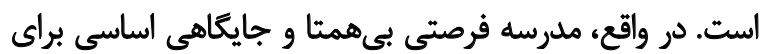

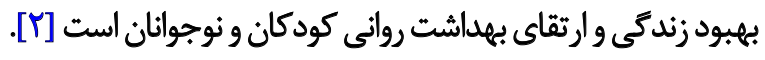


اشتياق تحصيلى داراى سه بُعد مجذوب تحصيل شدن، شوق

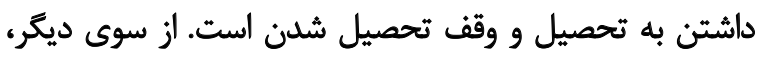

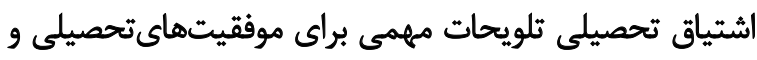
شعلى و اجتماعى دارد [1/]].

اشتياق تحصيلى سازماى است كه عملكرد تحصيلى را به طِور

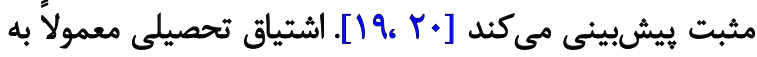

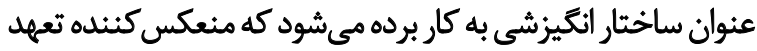

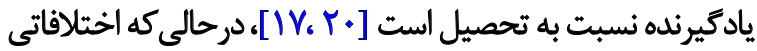

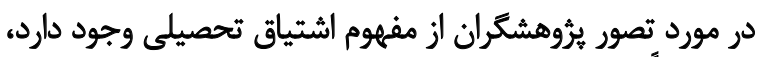

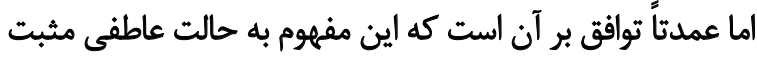

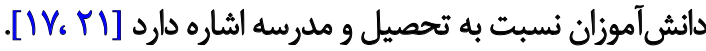
زمينههاي اجتماعى مانند يدر و مادر، معلم و محيط مدرسه،

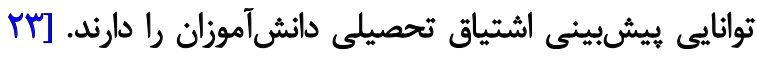

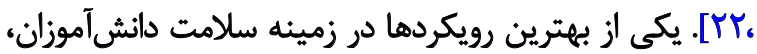

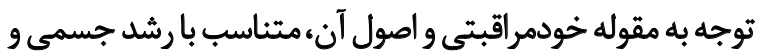

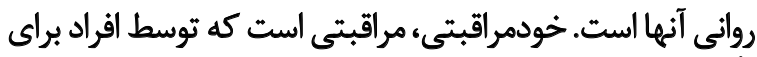

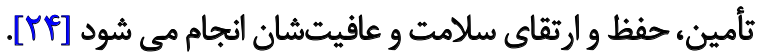

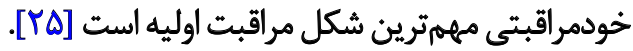

سازمان بهداشت جهانى خودمراقبتى راتوانيانيى افراد، خانوادهها

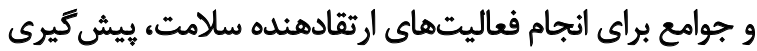

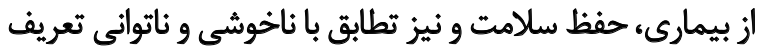

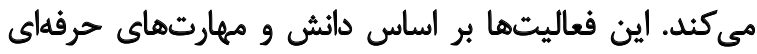

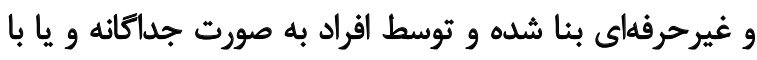

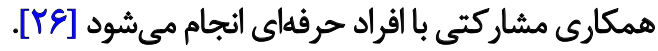
تخمين زده ميشود كه 90 تا هم درصد همه مراقبتهاى

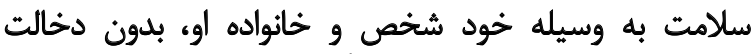

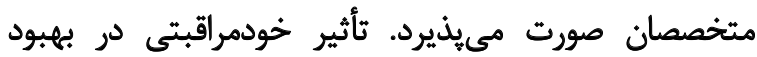
ييامدهاى سلامت و كاهش هزينهان مئها، در مطالعات متعدد به اثبات

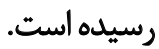

خودمراقبتى به جنبههايى كه تحت كنترل فرد هستند، تمركز

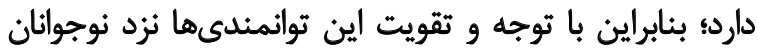

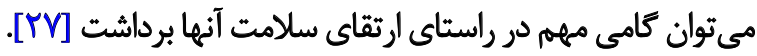
بخش عمده سال هاى از دست رفته عمر در كشور ما به سبب

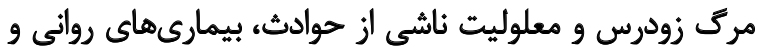

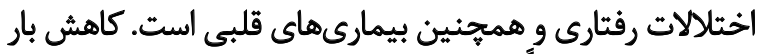

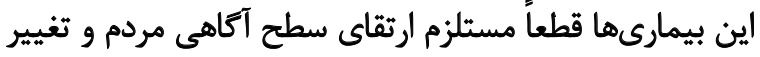

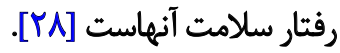

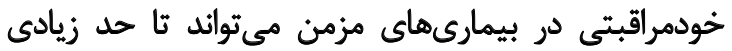

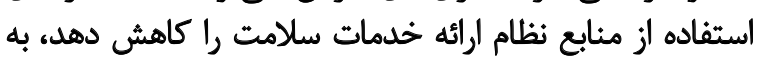

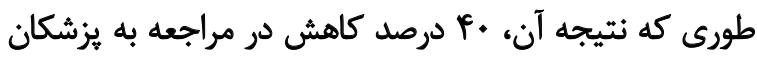

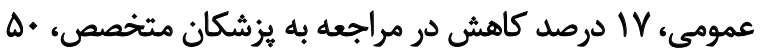

سا با إيامت روان، دانش و هنرى است كه به افراد كمك مي كند

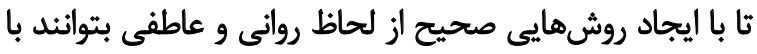

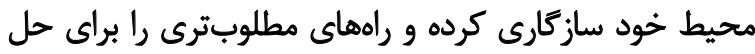
مشكلاتشان انتخاب كنيند [V]

سلامت روان، قدرت آرام زيستن و با خود و ديكران در دران

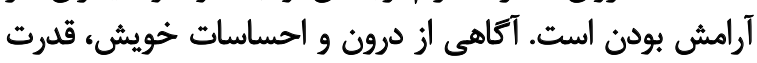

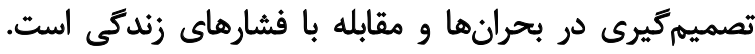

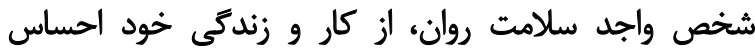
رضايتمندى مي كند [1]].

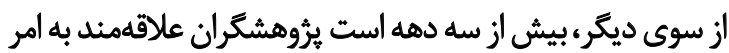

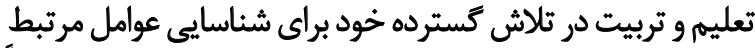

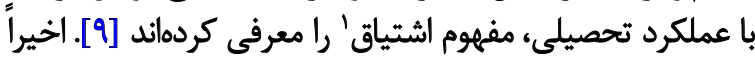

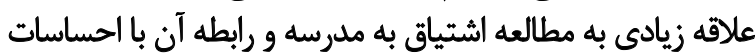

دانش آموزان در ارتباط با محيط اطراف خود وجود دارد [• [1].

همجنين يروهش در مورد اشتياق به مدرسه از زمانى شروع

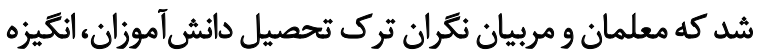

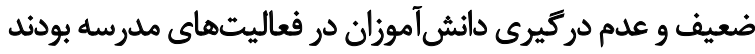

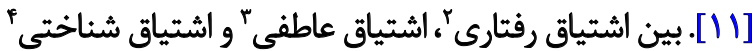

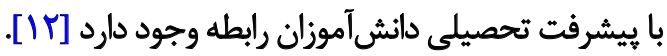
همجنين نتايج يُروهشى حاكى از آن بود معناي زندئي

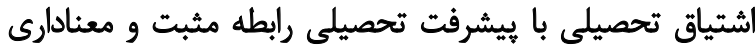

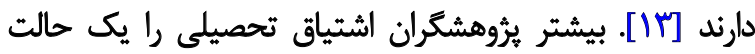

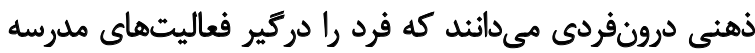

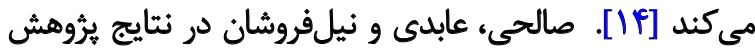

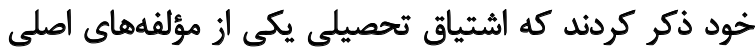

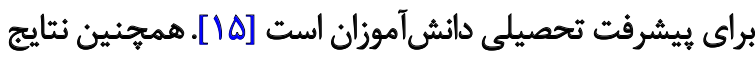

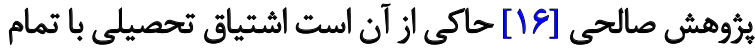

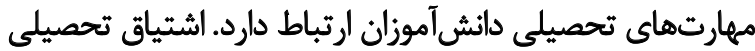

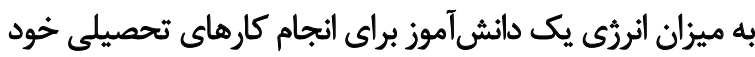

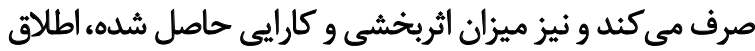

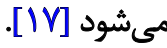

مدل فردريكز، بلومنفيلد و ياريس [1/] اشتياق تحصيلى را

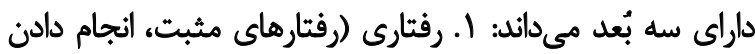

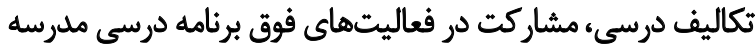

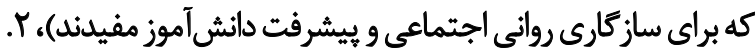

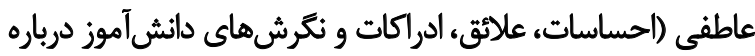

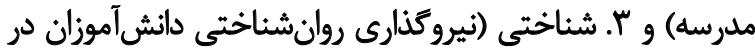
امر يادكيرى و كاربرد راهبردهاى خودتنظيمى آنهاست).

1. Longing

2. Behavioral Passion

3. Emotional Passion

4. Cognitive Longing 
بنابراين توجه سياست تذاران سيستم سلامت كشور در كنار

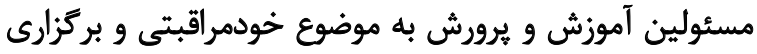

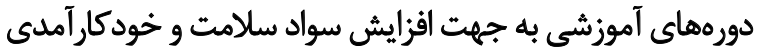

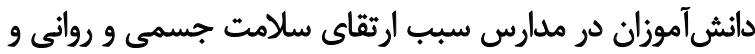

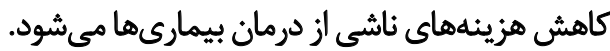

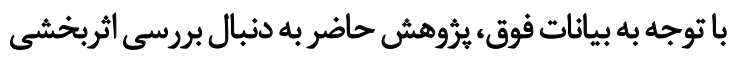

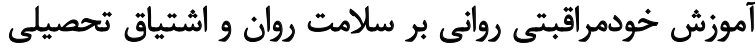
دانشي آموزان است. حونيت

$$
\text { مواد و روش ها }
$$

اين يُروهش از نوع مطالعات شبهآزمايشى و از نوع ييش آزمون

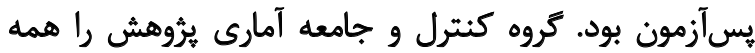

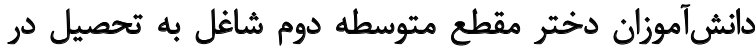

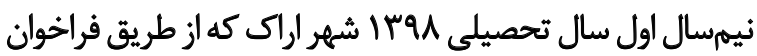
به مراكز مشاوره مدرسه مراجعه كردهاند، تشكيل دادهاندا

با توجه به جدول كوهن (دلاور، IrAF) و ميزان خطاى يك

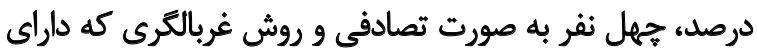

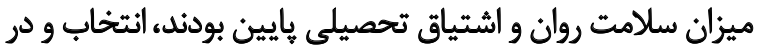

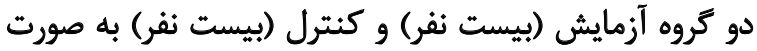
كمارش تصادفى جايكزينى شدند.

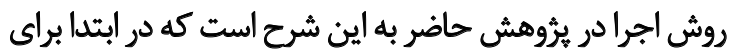

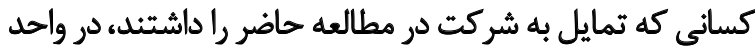

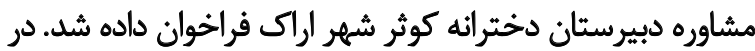

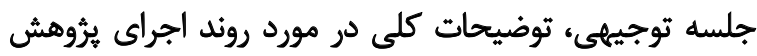

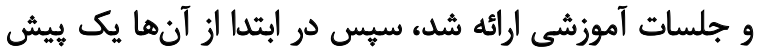
آزمون كرفته شد.

اين بيشآزمون شامل سه آزمون اشتياق تحصيلى، سازكارى آنس

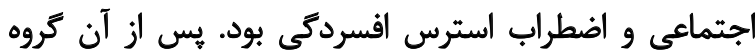

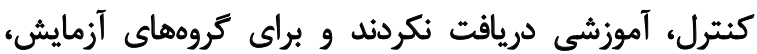

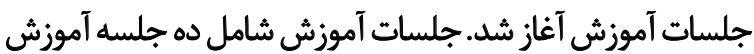

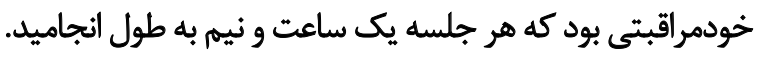

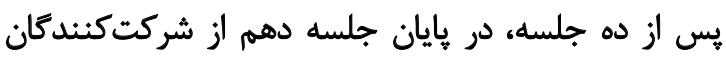

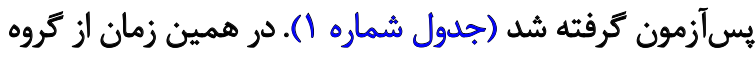

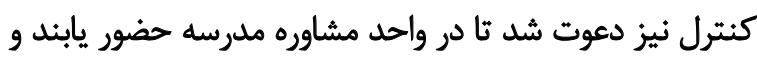

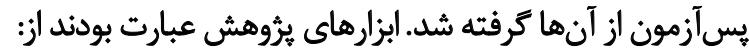

الف) يرسشنامه اشتياق تحصيلىه: اين يرسشنامه توسط

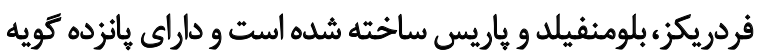

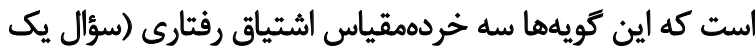

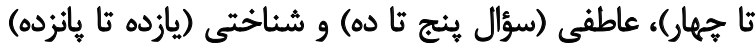

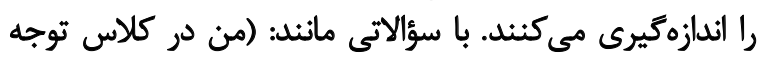

5. Academic Enthusiasm Questionnaire

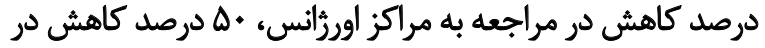

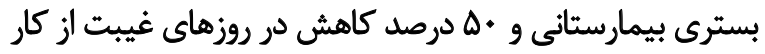

خواهد بود [7\%].

امروزه، مفهوم خودمراقبتى توجه متخصصين را باوجود كمبود

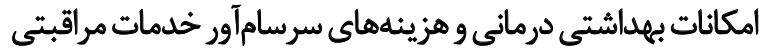

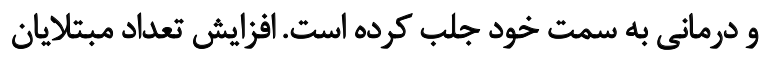

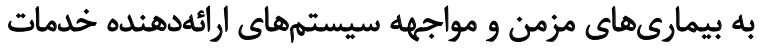

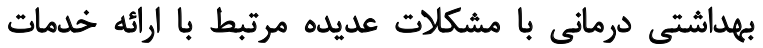

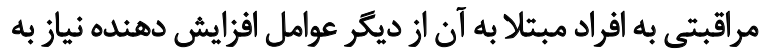

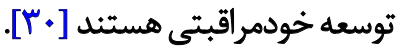

يكى از مهمترين تعيينكنيدههاى غيرطبى سلامت مبحث

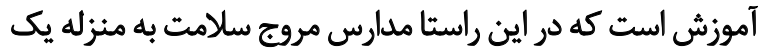

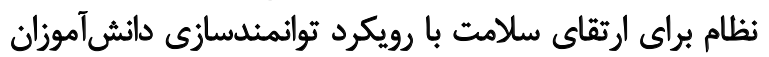

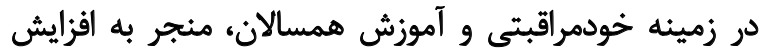

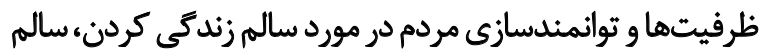

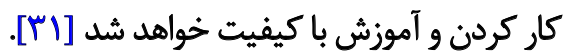

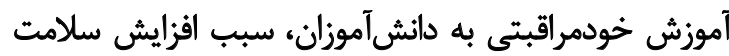

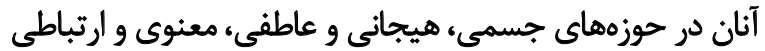

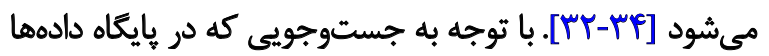

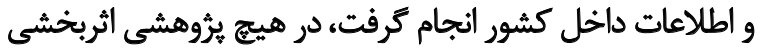
خودمراقبتى بر سلامت روان و اشتياق تحصيلى در إنى جمعيت

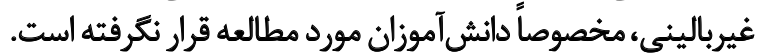

با توجه به اهميت سلامت در قشر نوجوان و آيندهاز هر آمران

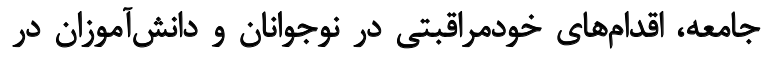

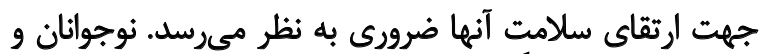

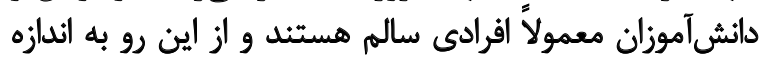
بالغين به سيستم بهداشتى مراجعه نمى كنئد

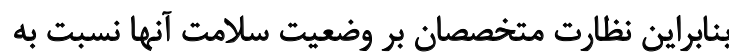

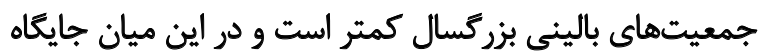

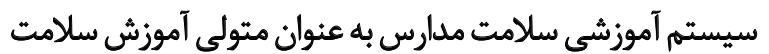

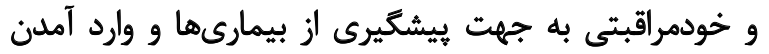

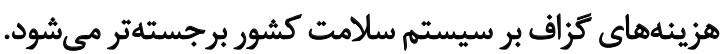
تلاش مدارس براى ارتقاى سطح سلامت روان و اشتياق

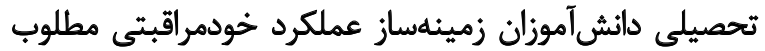

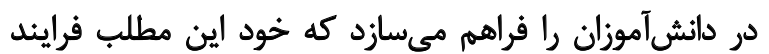

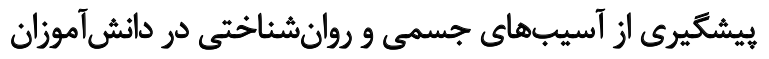

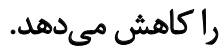

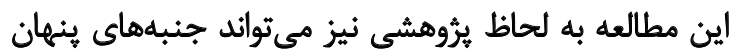

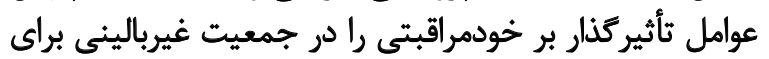

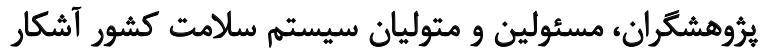

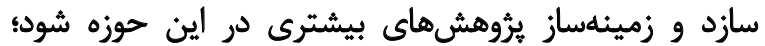


جدول ا. محتويات جلسات آموزشي در بروهش حاضر

\begin{tabular}{|c|c|}
\hline محتواى جلسات & جلسات \\
\hline موضوع: مهارتهاى ارتباطى (آموزش ارتباط مؤثر، كوش دادن فعال، شناسايى خطاهاى ارتباطى و... به صورت فعاليت كروهى و ايفاى نقش). & اول \\
\hline موضوع: مديريت خشم (شناسايى علائم خشم، شيوه ابراز مناسب خشم و كثترل خشم به صورت فعاليت كروهى و ايفاى نقش). & دوم \\
\hline موضوع: مليريت استرس (شناسايى عوامل ايجاد استرس، كثترل و كاهش استرس و آموزش ريلكسيشن به صورت فعاليت كروهى و ايفاى ثقش). & سوم \\
\hline موضوع: حل تعارض (تعريف مسئله، ثبت راهحلهاى مختلفه ارزيايى راهحلها و بركزيلن و اجراى راهحل به صورت فعاليت كروهى و ايفاى نقش). & جهارم \\
\hline موضوع: تاب آورى (تعريف تابآورى، عوامل ايجاد آن و تقويت تابآورى به صورت فعاليت كروهى و ايفاي نقش). & بپنجم \\
\hline موضوع: خودمراقبتى در افسردكى (علاتيم اقسردمى، شناسايى باورهاى منفى، جالش با باورهاى منفى به صورت فعاليت كروهى و ايفاى نقش). & ششمب \\
\hline موضوع: خودمراقبتى در فضاى مجازى (شناخت معايب و مزاياى فضاى مجزاى، كنترل عوامل نامطلوب به صورت فعاليت كروهى و ايفاى نقش). & هفتم \\
\hline موضوع: خودمراقبتى نر خشونت خانكى (تعريف خشونت خائكى و انواع آن، تهيه طرح كتثرل و محافظت در برابر خشونت خانكى به صورت فعاليت كروهى و ايفاى & هشتم \\
\hline موضوع: خودمراقبتى در هشكلات مربوط به خواب (شناسايى انواع هشكلات خواب، راههاى كثترل و كاهش آن به صورت فعاليت كروهى و ايفاى نقش). & ofi \\
\hline موضوع: خودمراقبتى در اعتياد (تعريف اعتياد، جرأتمندى و كتترل عوامل وسوسلبرائكيز به صورت فعاليت كروهى و ايفاى نقش). & دهم \\
\hline
\end{tabular}

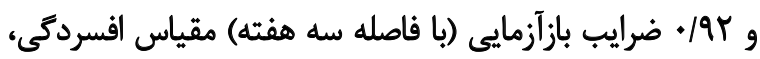

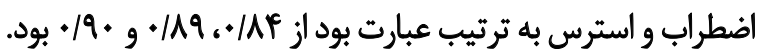

\section{طرح دمان}

طرح خودمراقبتى در سلامت روان و اعتياد يكى از اقدامات

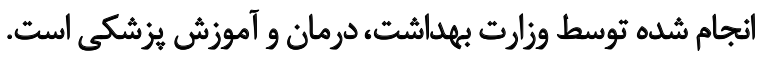

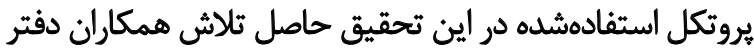

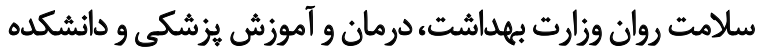

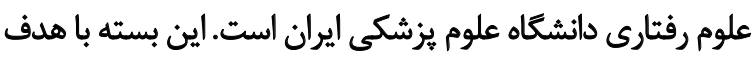

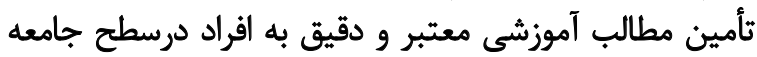
تنظيم شده است.

يافتهها

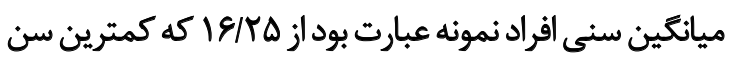

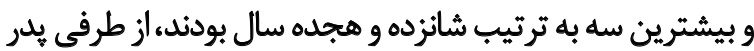

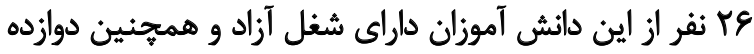

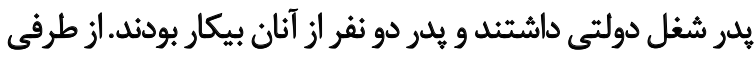

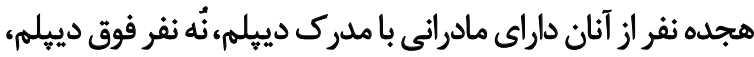
يازده نفر ليسائس و دو نفر فوق ليسانس بودند إندان

بهترين روش آمارى براى بررسى تفاوت تروهها با كنترل

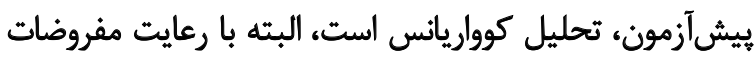

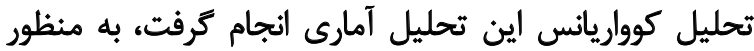

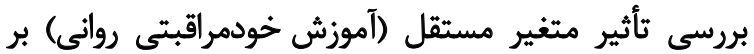

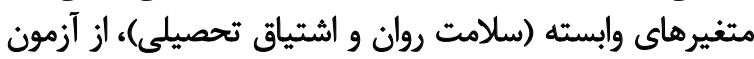

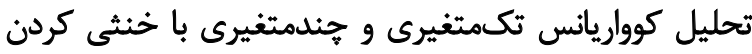

مى كنمي وقتى سر كلاس هستم فقط تظاهر مي كنم كه فعال

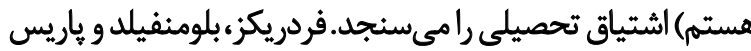

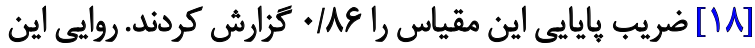

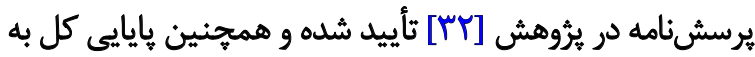

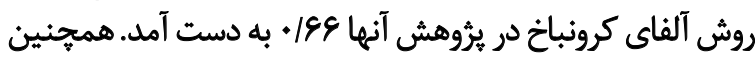

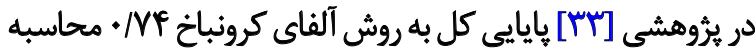

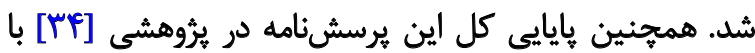

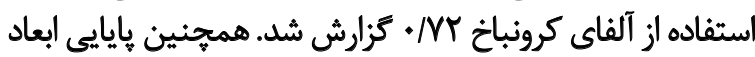

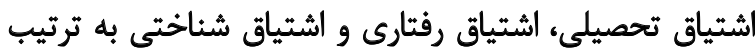

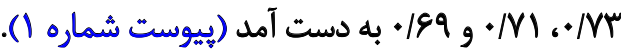

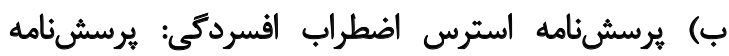

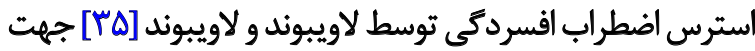

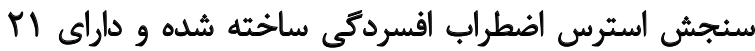

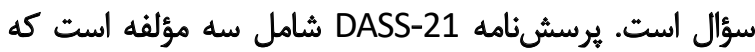

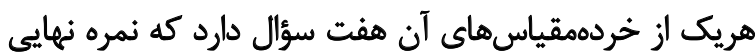

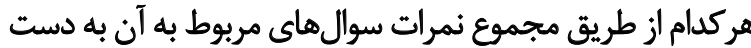

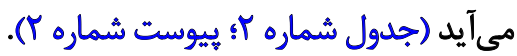

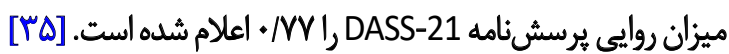

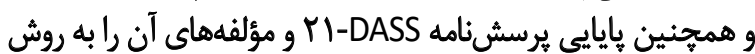

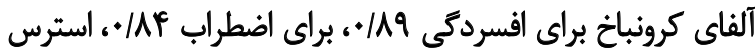

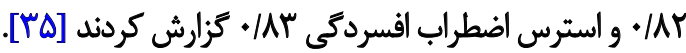

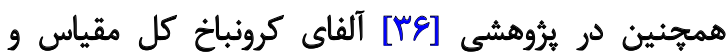

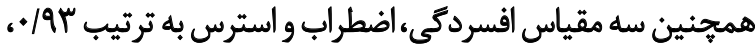

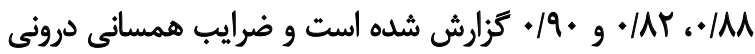

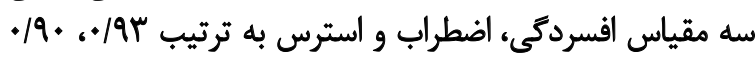


جدول r. ميانكين و انحراف استاندارد متغيرهاي يثروهش در دو كروه

\begin{tabular}{|c|c|c|c|c|c|}
\hline \multicolumn{4}{|c|}{ ميانكين \انحراف استاندارد } & \multirow{2}{*}{ مرهله } & \multirow{2}{*}{ تمروه } \\
\hline اثشياق & استرس & اضطراب & افسردكى & & \\
\hline & $q / q \Delta \pm r / A)$ & $1 . / \Delta \psi \pm \varphi / .$. & $1 . / r \Delta \pm \Psi / P A$ & ييش آزمون & \multirow{2}{*}{ كثترل } \\
\hline$r \Delta / A \Delta \pm V / A Y$ & $1 .|\Delta \Delta \pm P / M|$ & $1 \cdot(1 \cdot \pm f / 1)$ & $1 . / 9 \Delta \pm r / 8$. & يس آزمون & \\
\hline$r \Delta / \cdot . \pm N \cdot A$ & $1 . / r \cdot \pm r / g r$ & q/४ $\mathrm{r/ \Delta}$ & $1 \cdot 11 \cdot \pm r / q$. & ييش آزمون & \multirow{2}{*}{ آزيهايش } \\
\hline$r \Delta / r+ \pm N \Delta \mid$ & $N r+ \pm r / 19$ & $N E \Delta \pm T / N q$ & $N \Delta \cdot \pm r / A V$ & يسآزمون & \\
\hline
\end{tabular}

(1)

تحليل كوواريانس بين دو كروه روى نمرات تعديلشده متغير

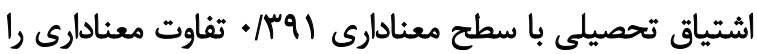

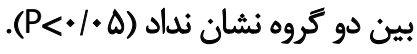
$5,5 d x$

هدف از يروهش حاضر بررسى اثربخشى آموزش خودمراقبتى

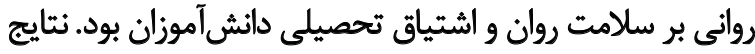

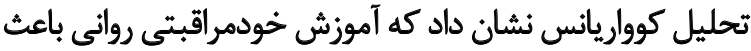

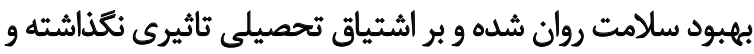
سطح آن تغييرى نكرده است.

يافته اول اين يروهش حاكى از آن است خودمراقبتى روانى

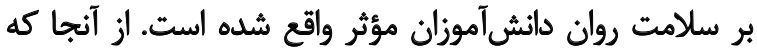

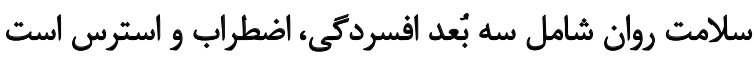

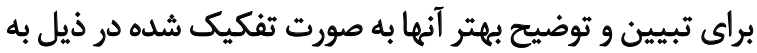
آنها برداخته شده است وتوضيت

نتيجه خردهمقياس افسردكى از فرضيه اين ثروهش مي تونواند

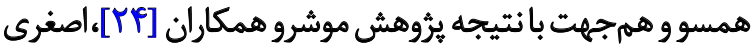

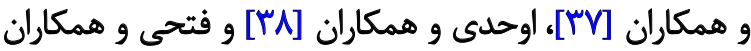

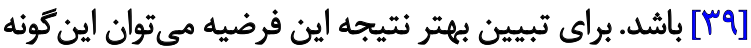
بيان داشت كه: طبق نظريه شناختى، افسردكى در نتيجه تحريفهاى شناختى
واريانس عامل يويش آزمون ها (تفاوتهاي اوليه بين آزمودني هاي

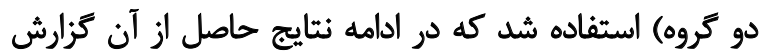
كرديله است.

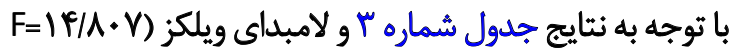

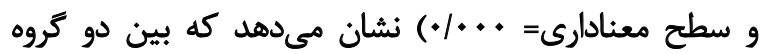

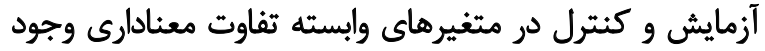

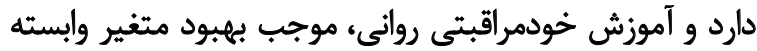

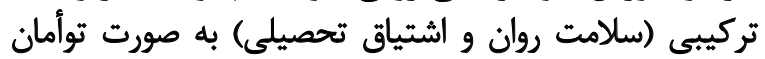
مى شئئ. براي تعيين مكان معنادار شدن آمارى اثر جندمتغيرى روى مئي

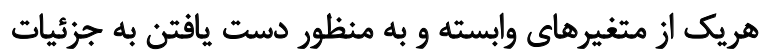

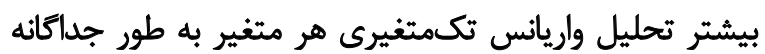

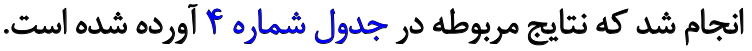
با توجه به نتايج جدول فوق، ننتايج تحليل كوواريانس بين دو كروه

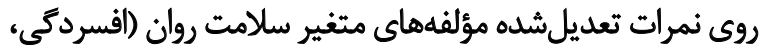

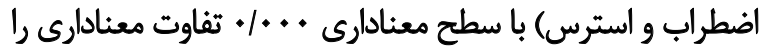

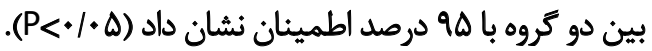
يعنى آموزش خودمراقبتي رواني موجب بهبود مؤلفههاي

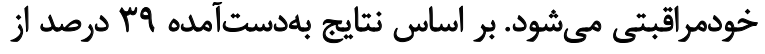

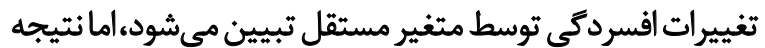

جدول ץ. نتايج تحليل كوواريانس جندمتغيره روى نمرات تعديلشده متغيرهاي وابسته بين دو كروه

\begin{tabular}{|c|c|c|c|c|c|c|}
\hline ضريب اثي & سطح معنادارى & درجه آزادى خطا & درجه آزادى فرضيه & $\mathbf{F}$ & ارزشُ & شاخص \\
\hline . $F \Delta F$ & $\%$ & m & f & If/A. & .180 & اثر بيلايي \\
\hline. $\mid F A F$ &.$\ldots$ & m & f & $1 F / A$. &.$/ M F$ & لامبداي ويلكز \\
\hline . IFAF & $.1 \ldots$ & m & e & $1 F / A$. & $1 / 91$ & اثر هوتلينى \\
\hline . & $+\cdots$ & r & $f$ & $\mid F / A$. & $1 / 91$ & اثر بزركترين ريشهروى \\
\hline
\end{tabular}


جدول F. نتايج تحليل كوواريانس جندمتغيره بين متغيرهاى يُوهش

\begin{tabular}{|c|c|c|c|c|c|c|c|}
\hline الندازه اثر & سطح معنادارى & $\mathbf{F}$ & ميانكين مجذورات & درجه آزادى & مجموع مجذورات & 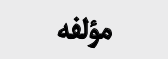 & هنبع \\
\hline \multirow[t]{2}{*}{.$/ 48$} & $\%$ & Ta/ru & $r \Delta / W$ & 1 & $r \Delta / w$ & افسردكى & \\
\hline & & & $\cdot / M$ & 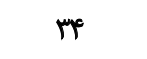 & นจ/৭४ & خطا & \\
\hline \multirow[t]{2}{*}{ (re } & $\%$ & IVqT & $r r / 19$ & 1 & $r \pi / 19$ & اضطراب & \\
\hline & & & $1 / 81$ & $m$ & $\Delta f / a r$ & خطا & 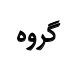 \\
\hline \multirow[t]{2}{*}{.$/ P D$} & $\%$ & TAVA & ry/ar & 1 & ry/ar & استرس & \\
\hline & & & $1 /$ & $\mu$ & $r v / n$ & خطا & \\
\hline \multirow[t]{2}{*}{. } &.$/ 49$ & . NO & V/re & 1 & V/re & اشتياق تحصيلى & \\
\hline & & & $81 / \% \Delta$ & $\varphi^{e}$ & 81/T" & خطا & \\
\hline
\end{tabular}

شود واز طريق تغيير آن شناختهاء، احساسات و واكنشهاي اعضا

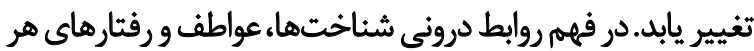

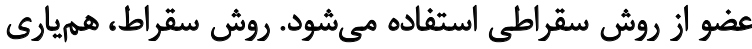

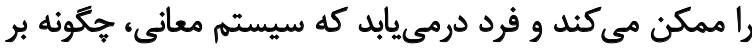

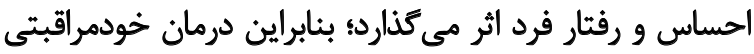

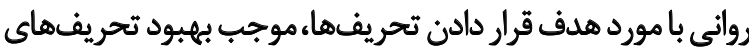

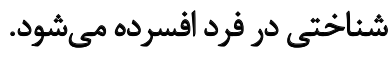
به عقيده بك، آنجه بيشتر موجب ناخشنودى افراد افسرده

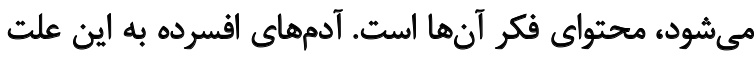

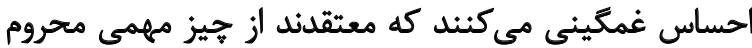

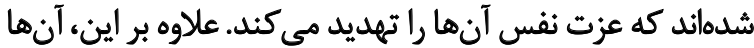
متقاعد شدهاند كه خودشان مسئول اين باخت هستئد إندا

نتحرشهاى كزّكار آنها باعث مىشود كه فرض كنند بى ارزش

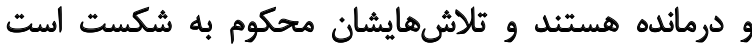

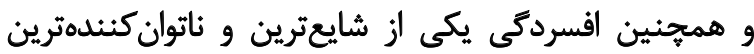

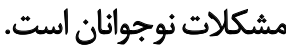

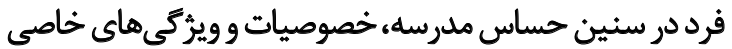

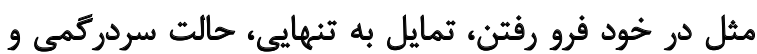

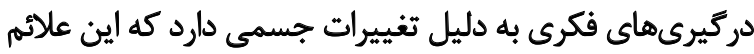

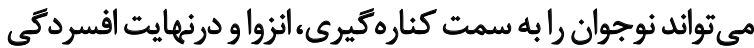

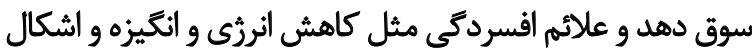

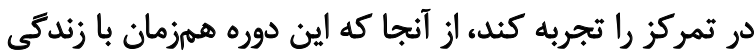

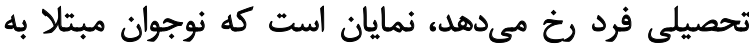
افسردكى از امر تحصيل بازمىماند.

يك دانش آموز بايد برنامه غذايى مناسب و دقيقى داشته باشد،

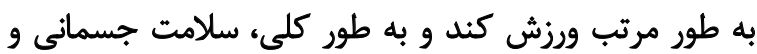

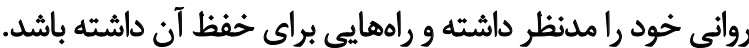

خاص در افراد به وجود مي آيد. اين تحريفها عبارتند از تعدادى

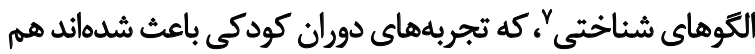
اطلاعات درونى و هم بيرونى به شيوهاى تحريف شده ادريه ادراك شوند. آرون بك^ معتقد بود كه افسردگى سه ضلع دارد. ا- نغكرش

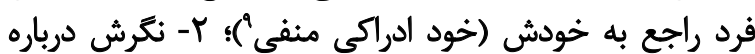

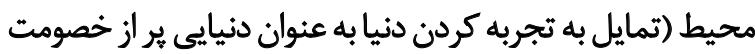

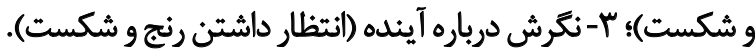

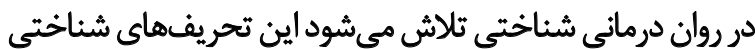

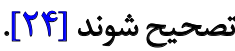

تحريفهاي شناختى يعنى خطاهايي كه افراد افسرده هنكام

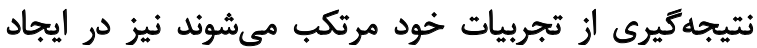

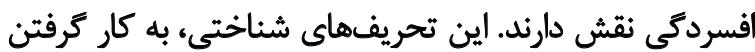

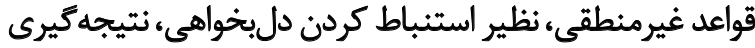

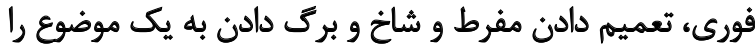

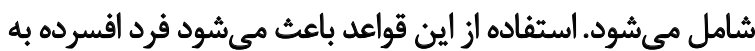

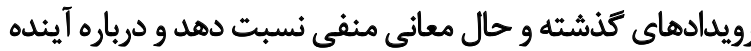

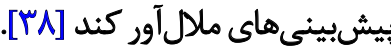
از طرفى جلسات اوليه، يادكيرى اصول نظرى شناختى رفتارى

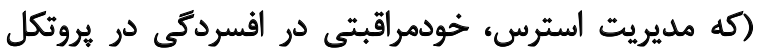

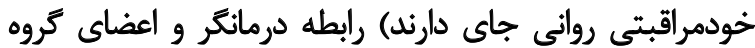

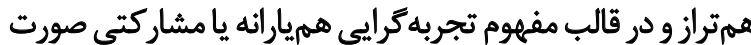

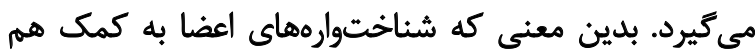

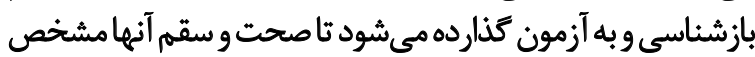

6. Specific Cognitive Distortions

7. Cognitive templates

8. Aaron Beck

9. Negative self precept 
مقى كند [• [f] تا موقعيتهاى اضطراب آور را شناسايى كند و براى

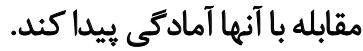

كابناين مىتوان بيان كرد آموزش خودمراقبتى روانى موجب إنى

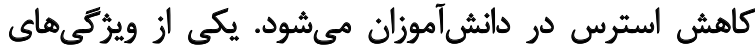

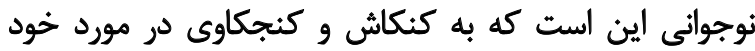

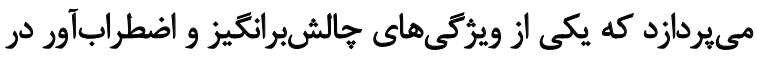
اين دوره است.

مشخص است كه نوجوانان در نتيجه اين شرايط با تغييرات

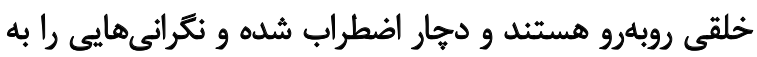

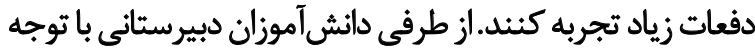

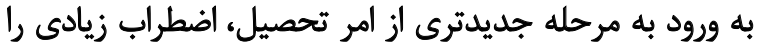

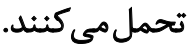

از طرفى آموزش خودمراقبتى حس ارزشمندى و برداشت

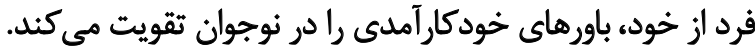

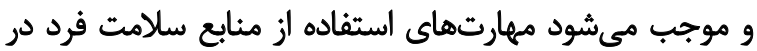

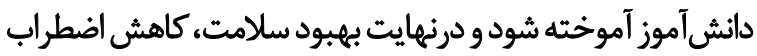

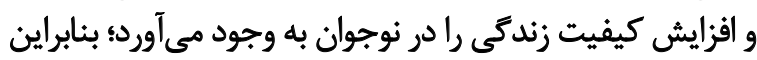

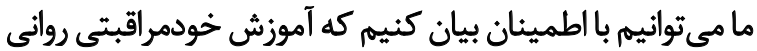

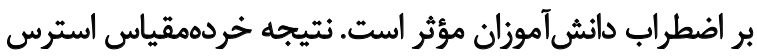

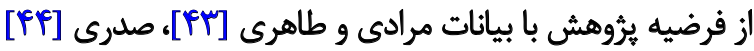

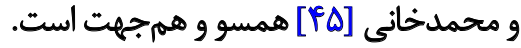

براي تبيين بهتر نتيجه اين فرضيه مي توان اينكونه بيان كرد

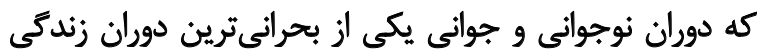

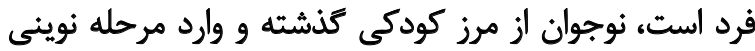

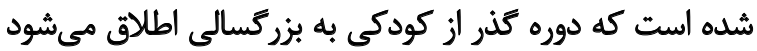

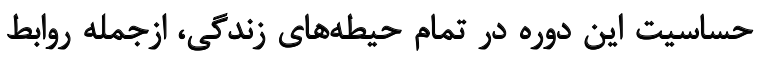

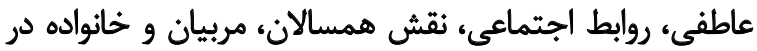
يروهشها و مطالعات بيان شده است.

همجنين بلوغ جسمانى و عاطفى در اين مرحله نوجوان رانيان رانيان

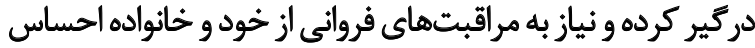

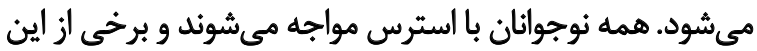

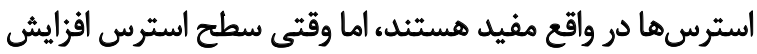

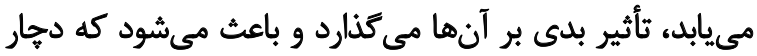

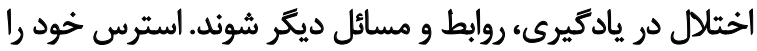

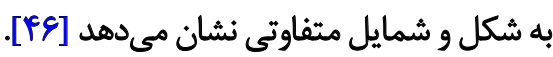

از ديدكاه ساراسون و ساراسون بيش فرض بنيادين رويكردهاى

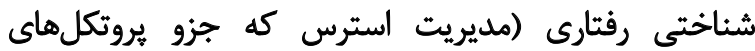

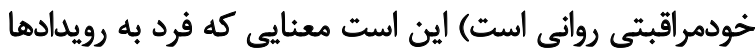

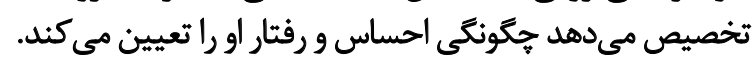

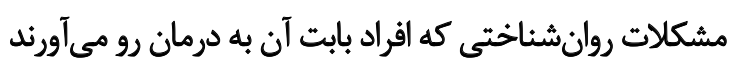
مانند اضطراب، افسردگى، عدم رضايت از روابط بينافي بافردى و غيره
تا يامد آن، كه رفتارهاى سالم هستند را براى خود رقم بزنند. آموزش خودمراقبتى اين امكان را به فرد مي دهد كه انوريى او

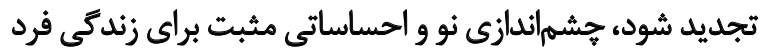

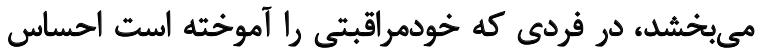

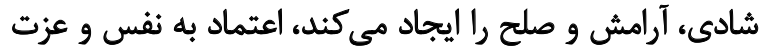

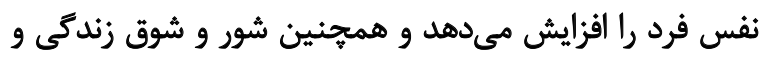

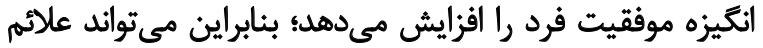

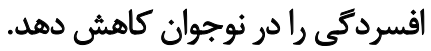

مي توان ادعا كرد براي بهبود شرايط دانش آموزان از آموزش بردي

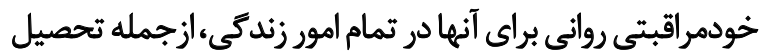

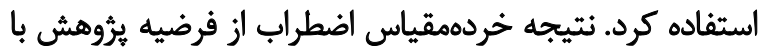

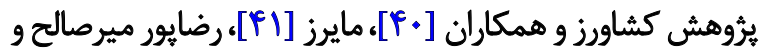

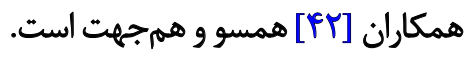

براي تبيين بهتر نتيجه اين فرضيه اين گونه مي توان بيان داشت

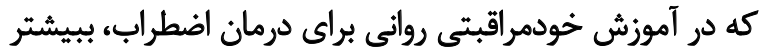

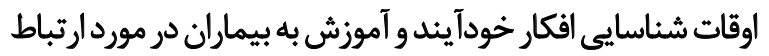

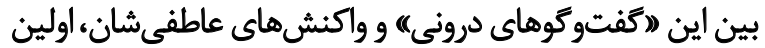
حوزهاى است كه توسط كروه مورد بروسى و و آزمون قرار مئى كيرد. در بعضى موارد به اعضاى كروه فرصت داده مي أشود تا وقايعى

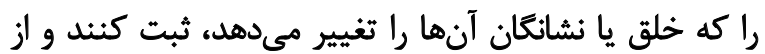

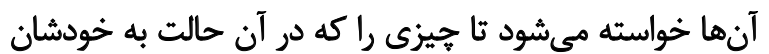

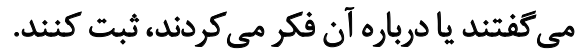

كاهى ممكن است از اعضاى كروه بخواهيم آخرين موقعيتى

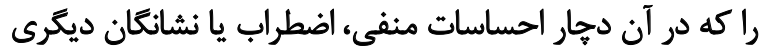

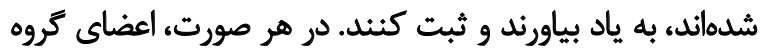

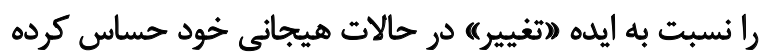

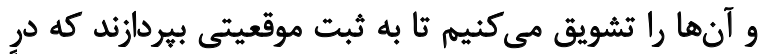

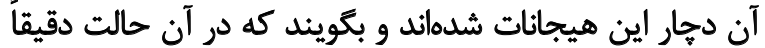
فكرشان جه بوده است.

اين كار ممكن است بسيار راحت و سرراست به نظر برسد،

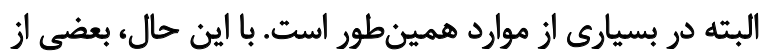

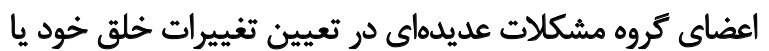
بيان افكارشان دارند.

روشهاي ديكرى نيز براى شناسايى اين افكار وجود دارد، يكى في

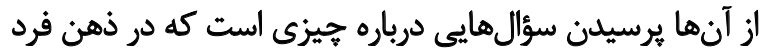

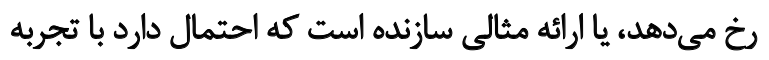

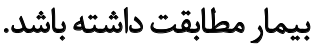

روش بديل ديكر اين است كه از فرد بخواهيم واقعهايى راكه در درد

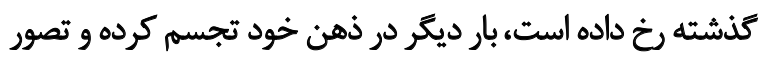

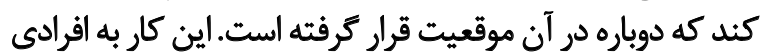

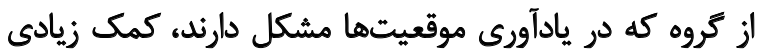


خود را به كار كيرد؛ بنابراين آموزش خودمراقبتى روانى ميىتواند

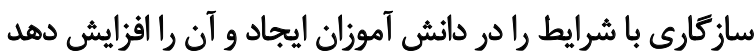

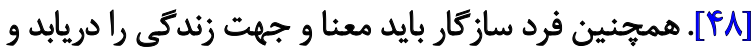

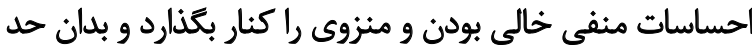

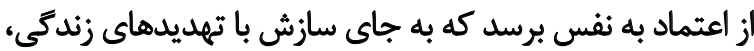

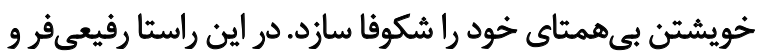

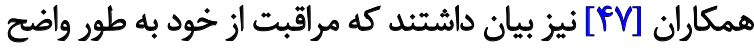

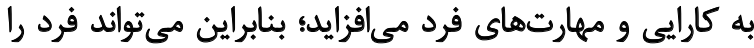

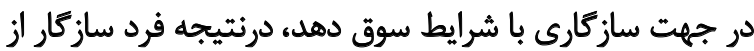

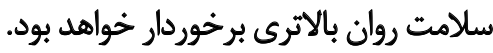

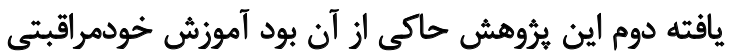

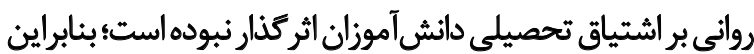

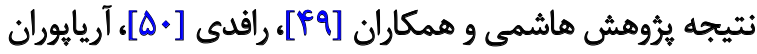

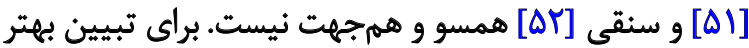

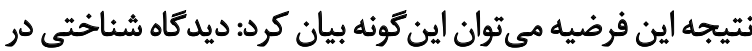

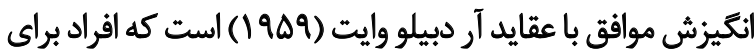

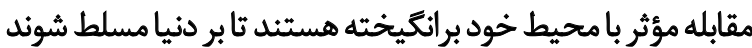
و اطلاعات را به نحو مؤثرتر يردازش كنيط يراند.

به نظر وايت، افراد اين كارها رانه به دليل نيازهاى زيستى، بلكه

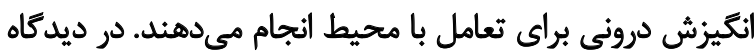

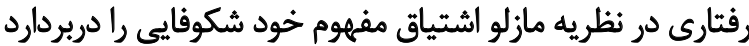

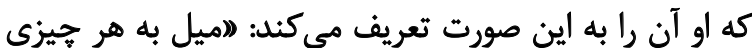

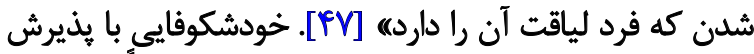

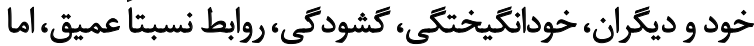

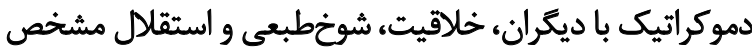

$$
\text { مىشود. }
$$

همجنين اشتياق تحصيلى در نظريه فردريكس، بلومنفيلد و ورئ

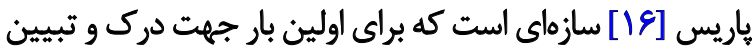

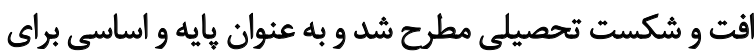

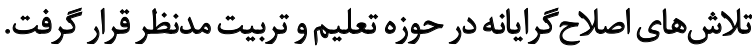
سازه اشتياق تحصيلى در روند تحصيلى زندكى دانش آموز و

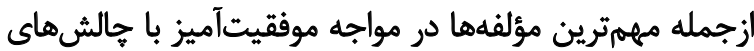

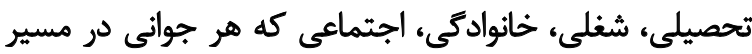

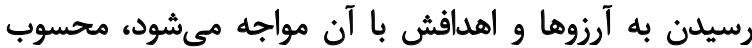

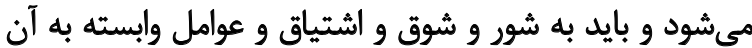

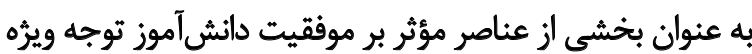
مبذول شود [QTة].

اشتياق تحصيلى سازهاى است كه به عنوان بايه و اساسى مري

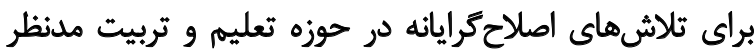

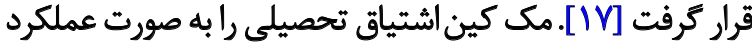

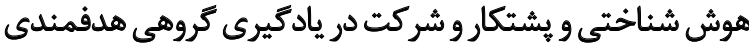

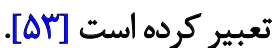

بدين دليل وجود دارند كه شخص ياسخى شناختى درونى به محيط خودش مى دهد كه غيرانطباقى است.

توفد هركونه درمان شناختى رفتارى، ازجمله درمان گروهى،

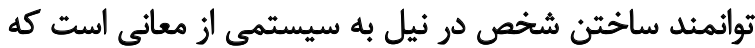

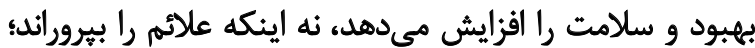

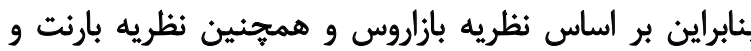

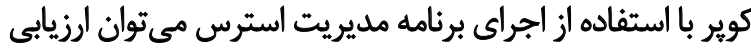
دائشآموزان رااز محيط تحت ثأثير قرار داد و استرس آنيها كاهش

يابِ.

افراد با ياد كرفتن خودمراقبتى رواثى قادر هستند در شرايط

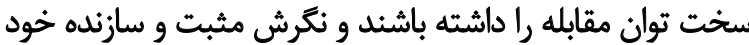

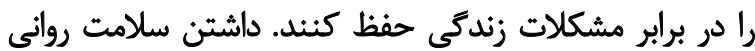
و عاطفى شامل وجود احساس رضايت، اعتماد به به نفس بادئ بالاء

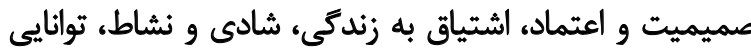
مقابله با استرس و ساز كارى با شرايط سخت و دشوار زندگى است

اين كزينهها با يادكيرى رفتارهاي خودمراقبتى در نوجوانان

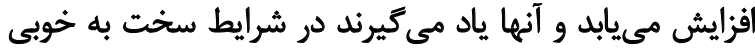

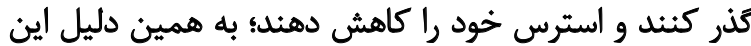

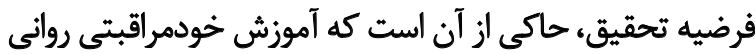

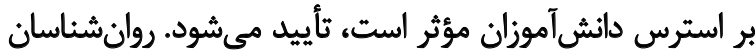

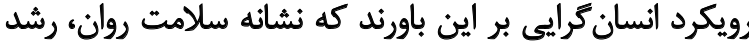

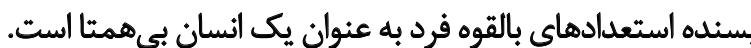

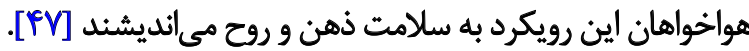
در نظريه رفتاركرايى به باور اسكينر، سلامث روان و انسان سالم

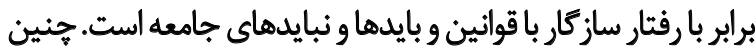

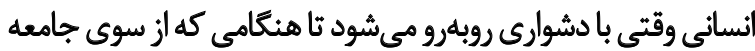

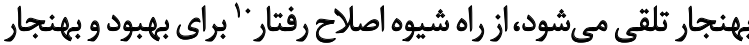

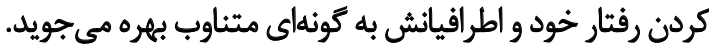
افزون بر آنه انسان سالم، آزادى را كونهاى توهم مى يندارد و

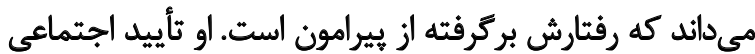

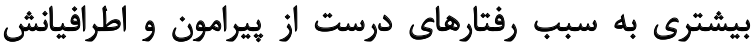

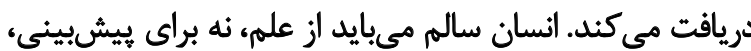

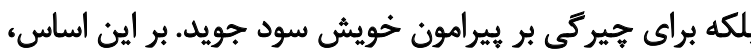

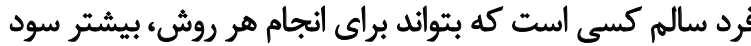

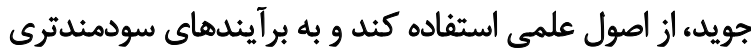

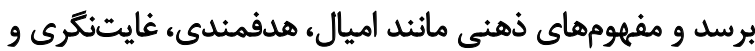

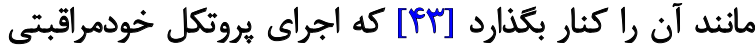

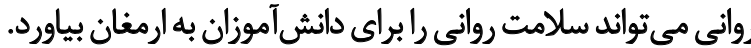
از طرفى به اعتقاد يرالت و مالو، خودمراقبتى به فرد آموزش

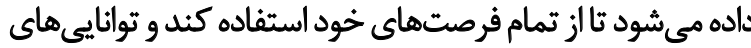

10. Behavior Modification 


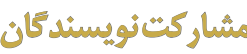

مفهومسازى، طراحى يروهش: زهرا زئ زئ مقدم و حسين

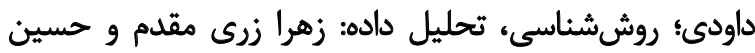
داوودى؛ جمعآورى داده: تمامى نويسندكان.

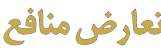

نويسندكان مقاله هيج كونه تعارضى در منافع اعلام نكردند.

$$
\text { 管 }
$$

از دانشعاه آزاد اسلامى واحد خمينى شهر براى يارى در انجام

$$
\text { يُروهش تقدير و تشكر مىشود. }
$$

اما از طرفى هدف از آموزش خودمراقبتى روانى افزايش و بهبود

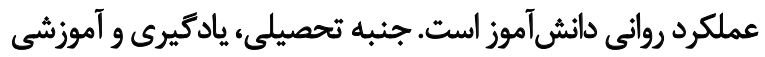

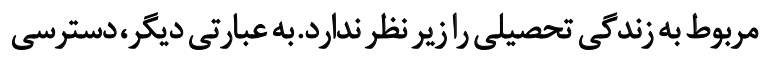

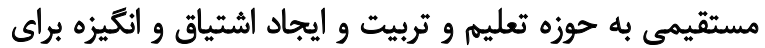

درس خواندن در زيرمؤلفههاى آموزش خودمراقيتى توريت روانى ندارند.

از اين جهت مي توان تبيين كرد كه به اين دلايل خودمراقبتى

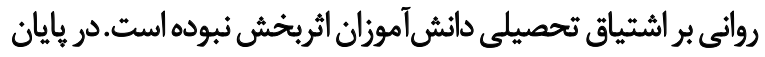

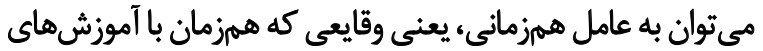

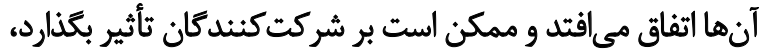

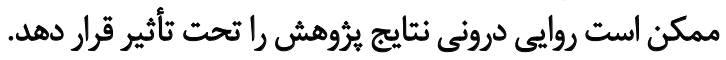

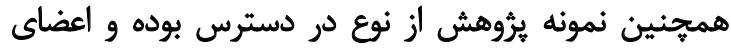

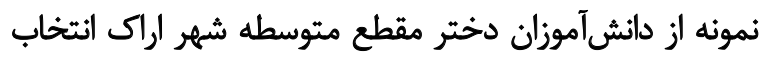

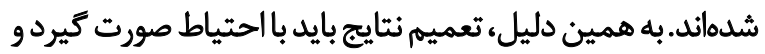

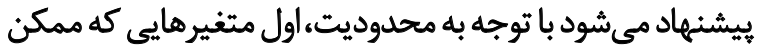
است درنتيجه آزمون اثر بكذارند، كنترل شوند.

با توجه به اينكه جامعه اين يرؤوهش دختران بودهاند، بيشنهاد

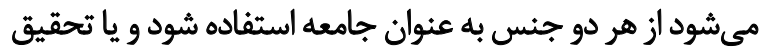

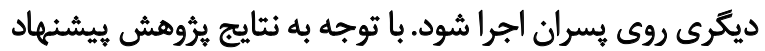

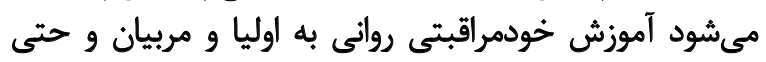
سفيران سلامت در مدارس ارائه شود.

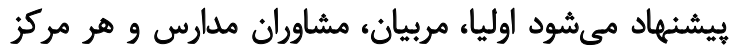

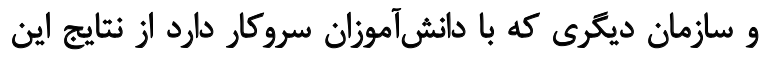

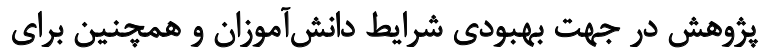

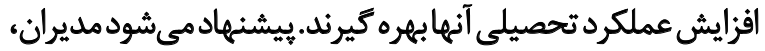

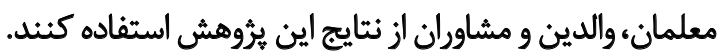

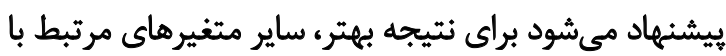

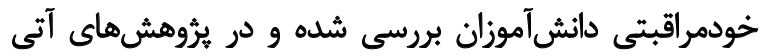
رابطه متغيرهاى وابسته اين يروهش بان بـ بكديكر مطالعه شوند.

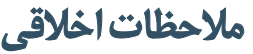

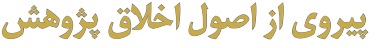

اين مقاله توسط كميته اخلاق دانشكاه آزاد اسلامى، واحد خمينى شهر تأييد شده است كميته (كد: IR.IAU.ARAK

.REC.1399.001

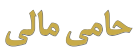

مقاله از رسالهى دكترى نويسنده دوم در گروه روانشناسى،

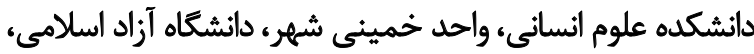
خمين استخراج شده است. 


\section{Reference}

[1] Atkinson M, Hoernby G. Mental health in schools [A Rahnama, M, Faridi, Persian trans.]. Tehran: Ayeezh; 2008.

[2] Collie RJ, Martin AJ. Teachers' sense of adaptability: Examining links with perceived autonomy support, teachers' psychological functioning, and students' numeracy achievement. Learn Individ Differ. 2017; 55:29-39. [DOI:10.1016/j.lindif.2017.03.003]

[3] Keating XD, Harrison L, Chen L, Xiang P, Lambdin D, Dauenhauer $B$, et al. An analysis of research on student health-related fitness knowledge in K-1 6physical education programs. J Teach Phys Educ. 2009; 28(3):333-49. [DOI:10.1123/jtpe.28.3.333]

[4] Alizadeh-Navaei R, Hosseini SH. [Mental health status of Iranian students until: A systematic review (Persian)]. Clin Exce. 2011; 2(1):1-10. [DOI:10.1123/jtpe.28.3.333]

[5] Najafi M, Foladjang M. [The relationship between self-efficacy and mental health among high school students (Persian)]. Daneshvar Behav. 2007; 14(23):69-81. https://www.sid.ir/fa/journal/ViewPaper. aspx?id=68184

[6] Maleki Pirbazari M, Nouri R, Sarami GH. [Social support and depression symptoms: The mediating role of self-efficacy (Persian)]. Contemp Psychol. 2011; 6(2):26-34. http://bjcp.ir/article-1-33-en.html

[7] Moradi A, Taheri S, Javanbakht F, Taheri A . [A meta-analysis on the relationship between mental health and social support in Iran (Persian)]. J Res Behav Sci . 2013; 10(6):565-73. https://rbs.mui.ac.ir/ browse.php?a id =289\&sid=1\&slc lang=en

[8] Baksheev GN, Robinson J, Cosgrave EM, Baker K, Yung AR. Validity of the 12-item General Health Questionnaire (GHQ-12) in detecting depressive and anxiety disorders among high school students. Psychiatry Res. 2011; 187(1-2):291-6. [DOl:10.1016/j.psychres.2010.10.010] [PMID]

[9] Maleki Pirbazari M, Nouri R, Sarami G. [Social support and depression symptoms: The mediating role of self-efficacy (Persian)]. Contemp Psychol. 2012; 6(2):26-34. http://bjcp.ir/article-1-33-en.pdf

[10] Zamanian A. [Nurses health study in shiraz hospitals (Persian)]. J Sch Public Health Inst Public Health Res. 2007; 5(4):47-54. https:// www.sid.ir/fa/Journal/ViewPaper.aspx?ID=80443

[11] Libbey HP. Measuring student relationship to school: Attachment, bonding, concectendness, and engagement. J Sch Health. 2004; 74(7):274-83. [DOI:10.1111/j.1746-1561.2004.tb08284.x] [PMID]

[12] Appleton JJ, Christenso SL, Furlong MJ. Student engagement with school: Critical conceptual and methodological issues of the construct. Psychol Sch. 2008; 45(5):369-86. [DOI:10.1002/pits.20303]

[13] Jalili R, Tanha Z, Hassanvand N. [Academic achievement: Relationship with achievement motivation and academic achievement (Persian)]. $7^{\text {th }}$ Iranian Scientific Conference on Educational and Psychological Sciences, Social and Cultural Injuries, 2018, Tehran, Iran. https://civilica.com/doc/882377/

[14] Mansouri L, Khalili Gashigani Z. [The relationship between meaning of life and academic achievement with academic achievement of the frst high school students in Izeh (Persian)]. Pper presented at $2^{\text {nd }}$ International Congress on Social Empowerment in the Field of Social Sciences, Psychology and Educational Sciences. 2017 Junuary 04; Tehran, Iran. https://civilica.com/doc/612688/

[15] Csikszentmihalyi M. Flow the psychology of optimal experiemce. $1^{\text {th }}$ ed. New York: Harper and Row; 1990. https://www.amazon.com/ Flow-Psychology-Optimal-Experience/dp/B0023Z9IL2
[16] Salehi R, Abedi M, Nilfroushan P. [Developing a conceptual mode of academic success: A qualitative study (Persian)]. Cult Psychother. 2019; 10(38):1-29. [DOI:10.22054/QCCPC.2019.35316.1948]

[17] Salehi R. [Investigating the relationship between academic passion and academic skills (Persian)]. Paper presented at: The $1^{\text {st }}$ National Conference on Sustainable Development in Iranian Education and Psychology. 2018 September 11; Tehran, Iran. https://civilica.com/ doc/824295/

[18] Fredricks J, Blumenfeld P, Paris A. School engagement: Potential of the concept, state of the evidence. Rev Educ Res. 2004; 74(1):59-109. [DOI:10.3102/00346543074001059]

[19] Eslami M, Dortaj F, Saadiipour E, Delawar A. [Causal modeling of personal and social resources for undergraduate students in undergraduate students of Tehran university (Persian)]. Couns Psychother. 2017; 7(28):133-61. [DOI: 10.22054/QCCPC.2017.7096]

[20] Saklofske D, Austin E, Mastoras S, Beaton S. Relationship of personality, affect, emotional intelligence and coping with student stress and academic success: Different patterns of association for stress and success. Learn Individ Differ. 2012; 22(2):251-7. [DOI:10.1016/j. lindif.2011.02.010]

[21] Lee J, Shute VJ. Personal and social- contextual factor in K-12 academic performance: An integrative perspective on student learning. Educ Psychol. 2010; 45(3):185-202. [DOI:10.1080/00461520.2010.493471]

[22] Wang M, Holcombe R. Adolescents' perceptions of classroom environment, school engagement, and academic achievement in middle school. Am Educ Res. 2010; 47(3):633-62. [DOI:10.3102/0002831209361209]

[23] Schwarzer R, Antoniuk A, Gholami M. A brief intervention changing oral self-care, self-efficacy, and self-monitoring. $\mathrm{Br} J$ Health Psychol. 2015; 20(1):56-67 [DOI:10.1111/bjhp.12091] [PMID]

[24] Mosher HJ, Lund BC, Kripalani S, Kaboli PJ. Association of health literacy with medication knowledge, adherence, and adverse drug events among elderly veterans. J Health Commun. 2012; 17(S3):241-51. [DOI $: 10.1080 / 10810730.2012 .712611]$ [PMID]

[25] Peyman N, Abdollahi M. [The relationship between health literacy and self-efficacy physical activity in postpartum women (Persian)]. $J$ Health Lit . 2016; 1(1):5-12. https://www.sid.ir/fa/journal/ViewPaper. aspx?ID=307528

[26] Schmidt U, Lee S, Beecham J, Perkins S, Treasure J, Yi I, et al. A randomized controlled trial of family therapy and cognitive behavior therapy guided self-care for adolescents with bulimia nervosa and related disorders. Am J Psychiatry. 2007; 164(4):591-8. [DOI:10.1176/ ajp.2007.164.4.591] [PMID]

[27] Khezrlu S, Fizi A. [Investigating the relationship between the perceived self-efficacy and self-care performance in patients with diabetes referring to Urmia Diabetes Clinic (Persian)]. Nurs Midwifery J. 2012; 10(3):369-75. http://unmf.umsu.ac.ir/browse.php?a id $=943 \&$ sid $=1 \&$ slc_lang=en

[28] Speirs KE, Messiria LA, Munger AL, Grutzmacher SK. Health literacy and nutrition behaviors among lowincome adults. J Health Care Poor Underserved. 2012; 23(3):1082-91. [DOI:10.1353/hpu.2012.0113] [PMID]

[29] Kindig DA, Panzer AM, Nielsen-BohIman L, editors. Health literacy: A prescription to end confusion. Washington, D.C.: National Academies Press; 2004. https://books.google.com/books?hl=en\&lr= 
[30] DeWalt DA, Berkman ND, Sheridan S, Lohr KN, Pignone MP. Literacy and health outcomes. J Gen Intern Med. 2004; 19(12):1228-39 [DOI:10.1111/j.1525-1497.2004.40153.x] [PMID] [PMCID]

[31] Sudore RL, Mehta KM, Simonsick EM, Harris TB, Newman AB, Satterfield $S$, et al. Limited literacy in older people and disparities in health and healthcare access. J Am Geriatr Soc. 2006; 54(5):770-6. [DOI:10.1111/j.1532-5415.2006.00691.x] [PMID]

[32] Sørensen K, Van den Broucke S, Fullam J, Doyle G, Pelikan J, Slonska $Z$, et al. Health literacy and public health: A systematic review and integration of definitions and models. BMC Public Health. 2012; 12:80. [DOI:10.1186/1471-2458-12-80] [PMID] [PMCID]

[33] Tehrani H. [Media health literacy (Persian)]. J Health Lit. 2016; 1(3):141-6. https://literacy.mums.ac.ir/article_10853_en.html

[34] Abbasi M, Dargah SH, Pirani Z, Bnyadi F. [The role of procrastination and motivational self-regulation in predicting students' academic achievement (Persian)]. Iran J Med Educ. 2016; 15(23):160-69. http:// ijme.mui.ac.ir/browse.php?a_code=A-10-2857-3\&slc_lang=en\&sid=1

[35] Safari H, Jenabadi H, Salm Abady M, Abbasi A. [Predicting academic passion based on spiritual intelligence and psychological hardiness (Persian)]. Educ Strategy Med Sci. 2016; 8(6):7-12. http://edcbmj.ir/ article-1-949-fa.html

[36] Lovibond SH, Lovibond PF. Manual for the Depression Anxiety Stress Scales. Sydney: Psychology Foundation; 1995. [DOI:10.1037/ t01004-000]

[37] Asghari M, Mohammad A, Saad F, Dibajania P, Zanganeh J. [Preliminary investigation of the validity and reliability of the Depression, Anxiety and Stress Scale (DASS) in clinical samples (Persian)]. Daneshvar Behav. 2008; 15(131):23-38. https://www.sid.ir/fa/journal/ViewPaper.aspx?id=119894

[38] Ouhadi L, Tajrobrhkar M. The effect of cognitive group therapy training on academic performance and anxiety, depression and stress of female high school students in Kerman. The first scientific research conference on psychology, educational sciences and pathology of society. 2015 September 01; Kerman, Iran. https://civilica. com/l/5982/

[39] Fathi N, Shahmoradi M, Sheikh S. [The Effectiveness of Life Skills Training on Mental Health and Personal - Social Adjustment of First Year High School Male Students in Shoush (Persian)]. J Educ Stud. 2015; 7(1):1-10. http://nama.ajaums.ac.ir/article-1-41-fa.html

[40] Keshavarz Gh, Nazari M, Zahrakar K, Sarami Gh. [The Impact of student group lifestyle training based on individual psychology approaches on reducing delay and increasing academic achievement in students (Persian)]. Fam Res. 2015; 12(26):107-24. https://www. sid.ir/fa/journal/ViewPaper.aspx?id=303665

[41] Myers JE, Sweeney TJ. Wellness counseling: The evidence base for practice. Couns Dev. 1998; 86(4):482-93. [DOI:10.1002/j.1556-6678.2008.tb00536.x]

[42] Rezapour Mirsaleh Y, Ahmadi Ardakani Z, Shiri M J. [The effectiveness of lifestyle change-based interventions with emphasis on educational lifestyle on educational self-concept of veterans' children (Persian)]. J Mil Med. 2018; 20(5):546-53. http://militarymedj.ir/ article-1-1744-fa.html

[43] Moradi A, Taheri S, Javanbakht F, Taheri A. [A meta-analysis on the relationship between mental health and social support in Iran (Persian)]. Res Behav Sci. 2013; 10(6):565-73. https://rbs.mui.ac.ir/ browse.php?a_id=289\&sid=1\&slc_lang=en
[44] Sadri B, brilliant M. [Interpersonal Cognitive problem solving program on aggression and anxiety reduction in primary school girls (Persian)]. Paper presented at: $4^{\text {th }}$ Iranian Scientific and Educational Conference on Social and Cultural Injury Psychology. 2016 September 10; Tehran, Iran. https://civilica.com/doc/565575/

[45] Mohammadkhani M, Azizian N. [The impact of life skills training on self-esteem, happiness, and academic stress in elementary sixth grade female students (Persian)]. Paper presented at: Second International Conference on Psychology, Education, and Humanities. 2019 May 22; Tehran, Iran. https://civilica.com/doc/897625/

[46] Khalatbari J, Azizzade Haghighi F. [The impact of life skills training programs and coping strategies on mental health in female students (Persian)]. Knowl Res Appl Psychol . 2012; 12(2):29-37. https://www. sid.ir/fa/journal/ViewPaper.aspx?ID=150029

[47] Rafieefar S, Attarzadeh M, Ahmadzad AM. [Comprehensive system of empowering people to take care of their health (Persian)]. Qom: Institute of Researchers Without Borders; 2007. http://www. ssu.ac.ir/cms/fileadmin/user upload/Moavenatha/MBehdashti/amozesh_salamat/pdf/nezam_jame_khod_moraghebaty.pdf

[48] Canada Department of National Health and Welfare. Health Services and Promotion Branch, Perreault R. Self-care: A review of the literature. Canada: Health and Welfare Canada; 1987. https://books. google.com/books?id=GZn5cQAACAAJ\&dq=Self-care:+A+review+of+t he+literature\&hl=en\&sa=X\&ved=2ahUKEwiWz-rRqsTyAhXqAmMBHS90A9wQ6AEwAHoECAcQAQ

[49] Hashemi S, Alipour A, Zare H, Aliakbari M. Fitting of self-degradable healthy biological pattern in Iranian students. Educ Sys Res. 2017; 11:36. https://scholar.google.com/scholar?hl=en\&as sdt $=0 \% 2 C 5 \& q=$ Fitting+of+Self-degradable+Healthy+Biological+Pattern +in+Iranian+Students\&btnG=

[50] Rafadi V. [The role of anger control training in adolescents 15 to 18 years in aggression reduction (Persian)]. [MA. thesis]. Tehran: University of Rehabilitation Sciences and Social Welfare; 2003. https:// ganj.irandoc.ac.ir//\#/search?keywords=

[51] Ariapooran S. [Comparing the emotion expression, emotional literacy and social self-efficacy in children with and without learning disabilities (Persian)]. J Learn Disabil. 2016; 5(2):7-26. http://jld.uma. ac.ir/article_389_367f3db24b6c4bf3288296313117f388.pdf?lang=en

[52] Saneghi A, Ahmady Kh. [The impact of life - goals training (based on life style) on educational motivation and, self - efficacy among secondary school students (Persian)]. J Sch Psy. 2016; 5(3):183-92. https://www.sid.ir/fa/journal/ViewPaper.aspx?id=279837

[53] Sobhi-Gharamaleki N. [The prediction of achievement motivation from students' emotional intelligence (Persian)]. J Sch Psy. 2014 1(3):49-62. https://www.sid.ir/fa/journal/ViewPaper.aspx?id=176216 
بيوست ا. هيرسشنامه اشتياق تحصيلى

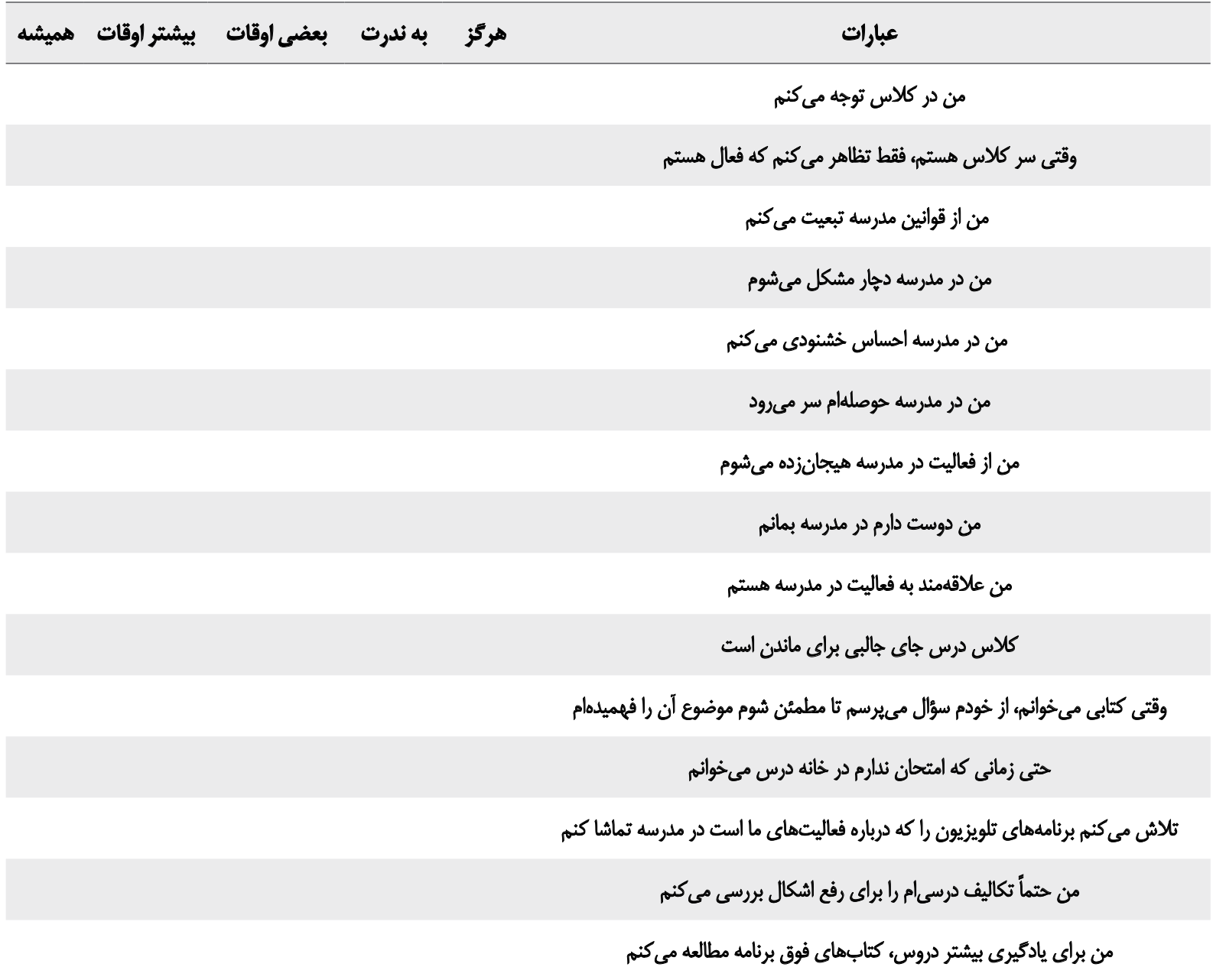




\begin{tabular}{|c|c|c|c|c|c|}
\hline \multirow[t]{2}{*}{ زياد } & متوسط & كي & اصلاً & \multicolumn{2}{|l|}{ جلات } \\
\hline & & & & برايم مشكل است آرام بكيرم & 1 \\
\hline & & & & متوجه شدم دهائم خشك مي شود & r \\
\hline & & & & فكر نمى كنم بتوانم هيج نوع احساس خوبى را تجربه كنم & r \\
\hline & & & & تنفس كردن برايم مشكل است & $f$ \\
\hline & & & & برايم سخت است در انجام كار ييش قدم شوم & $\Delta$ \\
\hline & & & & به موقعيتهايمم به طور اقراطى واكنش نشان مىدهم & 8 \\
\hline & & & & در بدنم احساس لززش ميكنم & $\checkmark$ \\
\hline & & & & احساس مى كنم انرزى روانى زيادى مصرف مى كنم & $\wedge$ \\
\hline & & & & نكراثم كه مبادا در بعضى هوقعيتها دهار ترس شوم يا به كار احمقانهاي دست بزنم & q \\
\hline & & & & احساس مي كنم هيزى ندارم كه منتظرش باشم & 1. \\
\hline & & & & خودم را يريشان و سردركم احساس مى كنم & 11 \\
\hline & & & & آرام بودن و در آرامش به سر بردن برايم مشكل است & ir \\
\hline & & & & احساس دل مردمى و دلشكسيكى دارم & ir \\
\hline & & & & نسبت به هر هيزى كه هرا از كار بازدارد، بى تحمل و نابردبارم (صبر و تحمل ندارم) & if \\
\hline & & & & احساس مي كنم كه در هر لحظه ممكن است دهار ترس و وحشت شوم & 10 \\
\hline & & & & قادر نيستم درباره خيلى جيزها شور و شوق از خود نشان دهم & 18 \\
\hline & & & & احساس مى كثم به عنوان يك فرد ارزش زيادى نلدارم & iv \\
\hline & & & & فكر مى كنم بسيار حساس و زودرنج هستم & M \\
\hline & & & & 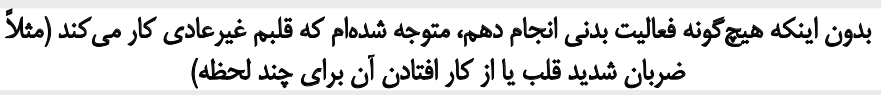 & 19 \\
\hline & & & & بلون هيج دليل موجهى احساس ترس مىكنم & r+ \\
\hline & & & & احساس مي كنم زندكى بي معنا است & r \\
\hline
\end{tabular}

